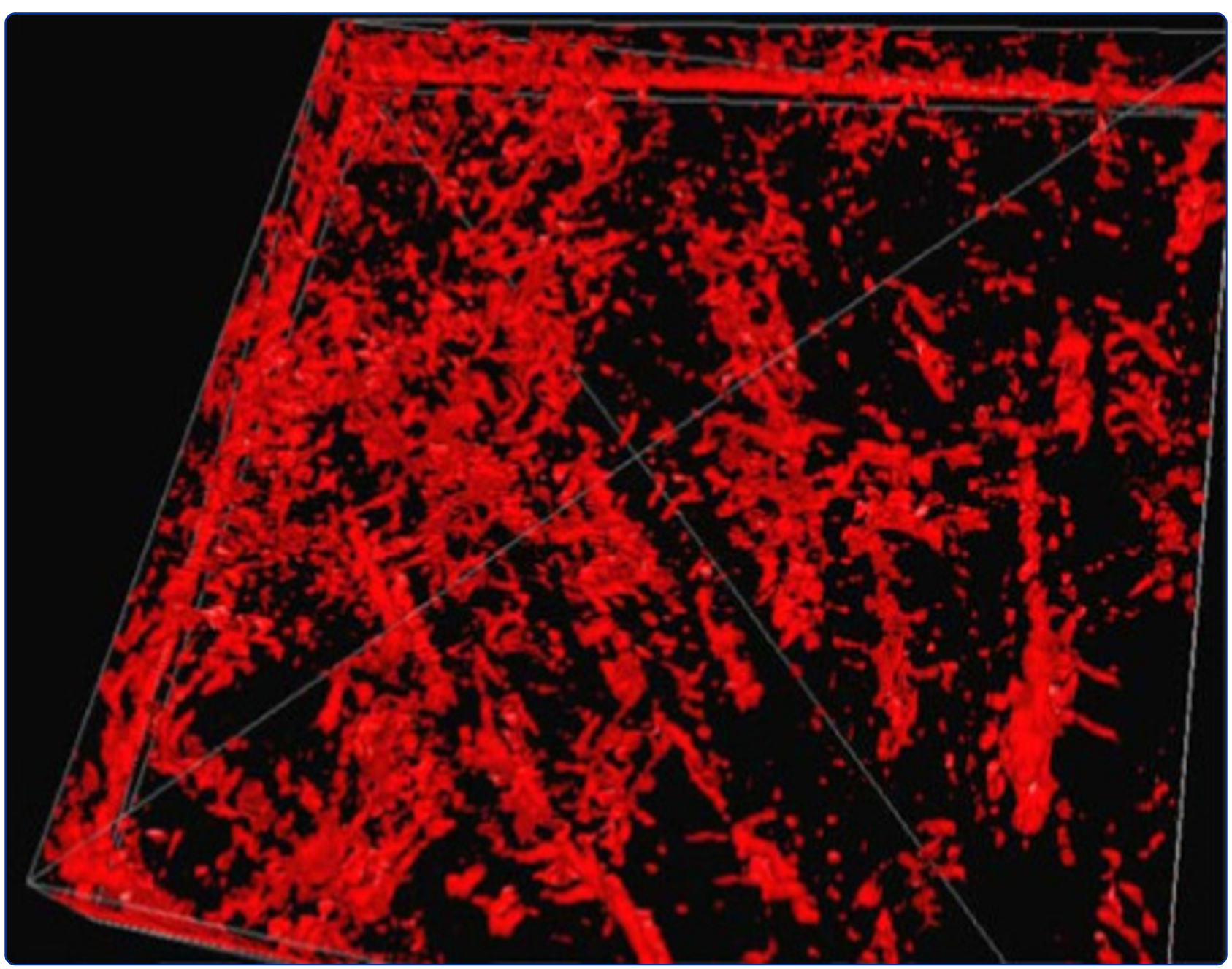

Amyloid beta dimers/trimers potently induce cofilin-actin rods that are inhibited by maintaining cofilin-phosphorylation

Davis et al. 


\title{
Amyloid beta dimers/trimers potently induce cofilin-actin rods that are inhibited by maintaining cofilin-phosphorylation
}

\author{
Richard C Davis ${ }^{1 \dagger}$, lan T Marsden ${ }^{1 \dagger}$, Michael T Maloney ${ }^{1,3}$, Laurie S Minamide ${ }^{1}$, Marcia Podlisny², \\ Dennis J Selkoe ${ }^{2}$, James R Bamburg ${ }^{1 *}$
}

\begin{abstract}
Background: Previously we reported $1 \mu \mathrm{M}$ synthetic human amyloid beta ${ }_{1-42}$ oligomers induced cofilin dephosphorylation (activation) and formation of cofilin-actin rods within rat hippocampal neurons primarily localized to the dentate gyrus.
\end{abstract}

Results: Here we demonstrate that a gel filtration fraction of 7PA2 cell-secreted SDS-stable human A $\beta$ dimers and trimers $(A \beta d / t)$ induces maximal neuronal rod response at $\sim 250 \mathrm{pM}$. This is 4,000-fold more active than traditionally prepared human A oligomers, which contain SDS-stable trimers and tetramers, but are devoid of dimers. When incubated under tyrosine oxidizing conditions, synthetic human but not rodent $A \beta_{1-42}$, the latter lacking tyrosine, acquires a marked increase (620 fold for $\mathrm{EC}_{50}$ ) in rod-inducing activity. Gel filtration of this preparation yielded two fractions containing SDS-stable dimers, trimers and tetramers. One, eluting at a similar volume to 7PA2 A $\beta d / t$, had maximum activity at $\sim 5 \mathrm{nM}$, whereas the other, eluting at the void volume (high-n state), lacked rod inducing activity at the same concentration. Fractions from 7PA2 medium containing A $\beta$ monomers are not active, suggesting oxidized SDS-stable $A \beta_{1-42}$ dimers in a low-n state are the most active rod-inducing species. $A \beta d / t-i n d u c e d$ rods are predominantly localized to the dentate gyrus and mossy fiber tract, reach significance over controls within $2 \mathrm{~h}$ of treatment, and are reversible, disappearing by $24 \mathrm{~h}$ after $A \beta \mathrm{d} / \mathrm{t}$ washout. Overexpression of cofilin phosphatases increase rod formation when expressed alone and exacerbate rod formation when coupled with $A \beta d / t$, whereas overexpression of a cofilin kinase inhibits $A \beta d /$ t-induced rod formation.

Conclusions: Together these data support a mechanism by which $A \beta d / t$ alters the actin cytoskeleton via effects on cofilin in neurons critical to learning and memory.

\section{Introduction}

Proteolytic cleavage of amyloid precursor protein (A $\beta$ PP) by $\beta$ - and $\gamma$-secretases gives rise to $A \beta$ peptides ranging in length from 36-43 amino acids [1-6]. Early onset familial AD is linked with high penetrance to mutations that lead to increased production of the most amyloidogenic species, $A \beta_{1-42}$ [4,7-10]. The "amyloid hypothesis" proposes that increasing cerebral accumulation of $A \beta$ over years to decades exacerbates cognitive decline, neurodegeneration, and senile plaque deposition

\footnotetext{
* Correspondence: jbamburg@lamar.colostate.edu

+ Contributed equally

'Department of Biochemistry and Molecular Biology, Colorado State

University, Fort Collins, CO 80523-1870, USA

Full list of author information is available at the end of the article
}

associated with $\mathrm{AD}$. Elevated $\mathrm{A} \beta$ can result from mutations or allele expression patterns (or both) that enhances its production/aggregation or decreases its clearance/degradation [2].

The concept that different isoforms and/or conformations of $A \beta$ deliver independent signals to neurons is widely supported [11]. Although the term $A \beta$ is used to describe a spectrum of peptide species, the effects of different $A \beta$ peptide species on neuronal function or morphology are not the same [12,13]. Emphasis has been placed recently on the characterization of small soluble oligomeric forms of $A \beta$, sometimes referred to as $A \beta$-derived diffusible ligands (ADDLs) [14]. Unlike synthetic $A \beta$ peptide oligomers or fibrils, which generally are used at $\mu \mathrm{M}$ or greater concentrations, ADDLs are

\section{C) Biomed Central}


toxic to cultured neurons at nanomolar concentrations [15] and at $500 \mathrm{nM}$ they prevent high frequency stimulation-induced long-term potentiation (LTP) [16]. Furthermore, ADDLs have been linked to hippocampusdependent temporal memory deficits in mice $[17,18]$.

An even more potent synaptic-inhibitory preparation of human $A \beta$ containing SDS-stable dimers and trimers $(A \beta d / t)$ has been obtained by gel filtration of culture medium of a $\mathrm{CHO}$ cell line (7PA2) expressing a mutant human A $\beta$ PP [19]. When used at physiologically relevant (sub-nanomolar) concentrations to treat hippocampal slices, the $A \beta d / t$ fraction, as well as a fraction containing SDS-stable A $\beta$ dimer extracted from postmortem human AD brain, strongly inhibited the development of LTP and enhanced long-term depression (LTD), electrophysiological correlates of learning and memory defects in intact animals [20,21]. Although the presence of both $A \beta$ monomer and dimer in Trisbuffered saline (TBS) and TBS/Triton extracts of human brain correlates well with Alzheimer-type dementia [22], it is only the fraction containing SDS-stable dimer that has strong inhibitory activity on the establishment of LTP in acute hippocampal slices [21]. Single intracerebral ventricular (i.c.v.) infusions into adult rat brain of either $\mathrm{A} \beta \mathrm{d} / \mathrm{t}$ from 7 PA2 cells or $\mathrm{A} \beta$ dimer from $\mathrm{AD}$ brain caused transient memory and learning deficits [19-21,23,24]. Infusion (i.c.v.) of $A \beta d / t$ into adult rat brain several hours after training inhibits synaptic remodeling that accompanies learning and memory consolidation by preventing a transient increase in the number of synapses in the dentate gyrus [24]. Although their mechanism is unknown, the SDS-stable A $\beta$ dimer and $\mathrm{A} \beta \mathrm{d} / \mathrm{t}$ cause synaptic dysfunction at sub-nanomolar concentrations, which are $10^{3}-10^{4}$ fold lower than commonly used traditionally prepared oligomeric forms of synthetic $A \beta$ (A $\beta$ syn) and $10^{2}-10^{3}$ fold lower than concentrations of ADDLs. Indeed, direct comparison by i.c.v. injection of cell-derived and $A \beta$ syn oligomers on cognitive impairment in rats confirms the large activity differences between peptide species [25].

In addition to the classical hallmarks of AD pathology that include amyloid plaques and phospho-tau-containing neuropil threads and neurofibrillary tangles, histopathological structures involving actin and the actin-binding protein, cofilin, have been identified in AD brain (reviewed in [26]). Rod-shaped arrays of cofilin-saturated actin bundles (cofilin-actin rods) are induced in cultured hippocampal neurons and organotypic hippocampal slice cultures in response to mitochondrial dysregulation (ATP-depletion) [27-30], oxidative stress [27,31], excitotoxic glutamate [27], extracellular ATP [32], overexpression of cofilin [33], and exposure to $A \beta$ oligomers $[29,34]$, each of which is a potential mediator of synaptic loss observed in both familial and sporadic AD (reviewed in [35]). Rods contain actin and cofilin in a 1:1 complex [36], they form in tandem arrays (striations) within neurites, and they serve as sites for accumulation of phosphorylated tau $[37,38]$, suggesting that they may play a role in formation of striated neuropil threads, the major tau pathology in human AD brain. Cofilin-actin rods can grow to completely occlude the neurites in which they form causing microtubule loss [27] and thus inhibit vesicular transport $[34,39]$. Because an early indication of AD is blockage in axonal transport that leads to axonal swellings [40,41] and synaptic loss [42], we investigated the ability of physiologically relevant amounts of $\mathrm{A} \beta \mathrm{d} / \mathrm{t}$ to induce cofilin-actin rod formation in rat hippocampal neurons and organotypic slices. We examined activity of A $\beta$ syn and showed that its oxidation yielded a product that was $\sim 1000$ fold more active in rod induction. The dose, time course and reversibility of $A \beta d / t$ rod formation, along with the location of rods in the hippocampus, all suggest that cofilin-actin rods are likely mediators of $\mathrm{A} \beta \mathrm{d} / \mathrm{t}$-induced synaptic dysfunction leading to memory and learning deficits.

\section{Materials and Methods \\ Reagents}

All chemicals are reagent grade and were obtained from Sigma-Aldrich Co. and all tissue culture reagents were from Life Technologies (Invitrogen, Carlsbad, CA). Synthetic amyloid- $\beta$ peptide $\left(A \beta_{1-42}\right)$ and a scrambled peptide with the $A \beta_{1-42}$ amino acid composition were purchased from AnaSpec, Inc. (San Jose, CA). A $\beta$ monomer and dimer/trimer fractions were prepared from the culture medium of CHO 7PA2 cells [19] as previously described [20,43], and unless noted otherwise were used at $1 \mathrm{X}$ concentration (equivalent to their secreted concentration in the medium which was determined below). Similar fractions obtained from culture medium of wild type $\mathrm{CHO}$ cells were used as controls.

\section{Culture treatments of dissociated neurons and slices}

Synthetic A $\beta$ oligomers were made by solubilizing the peptide in hexafluoroisopropanol and drying in $10 \mu \mathrm{g}$ aliquots. Each $10 \mu \mathrm{g}$ of synthetic $\mathrm{A} \beta_{1-42}$ was solubilized in $10 \mu \mathrm{L}$ of DMSO, diluted with $78.6 \mu \mathrm{L}$ of sterile Ham's F-12 (to yield a $25 \mu \mathrm{M}$ stock) and incubated $24 \mathrm{~h}$ at $4^{\circ} \mathrm{C}[34,44,45]$. Scrambled peptide was prepared identically and both scrambled peptide and synthetic $A \beta_{1-42}$ oligomers were added to final concentration of $1 \mu \mathrm{M}$. The 7PA2 cell secreted A $\beta$ fractions (monomer or $d / t$ ) or the corresponding fractions from control medium, were prepared as described [20] and, after gel filtration, were freeze-dried to remove the ammonium acetate buffer. These were reconstituted to $5 \mathrm{X}$ or $10 \mathrm{X}$ in culture medium and diluted with culture medium to achieve the desired final concentrations. Peroxide oxidized $A \beta_{1-42}$ 
dimer was prepared from synthetic human $A \beta_{1-42}(5 \mu \mathrm{M})$ by incubation in PBS in the presence of hydrogen peroxide plus or minus $\mathrm{Cu}^{2+}$ as previously described [46-48]. After 3 days in peroxide alone or 5 days in peroxide plus $\mathrm{Cu}^{2+}$, the mixture was assayed directly for rod inducing activity in dissociated neuronal cultures (see below) or was fractionated by gel filtration using the same column and elution conditions for preparing the 7PA2 $A \beta d / t$. The fractions were also assayed for rod inducing ability and for $A \beta$ content using the dot blot assay (see below).

\section{Animals}

Timed pregnant Sprague Dawley rats were obtained from Harlan (Indianapolis, IN). E18 fetal rat hippocampal neurons were obtained from timed-pregnant dams and were frozen for future culture work as per published methods [49]. Pups were sacrificed on postnatal days 6-10 for slice preparation. Animal studies were performed according to the National Research Council's guide for care and use of laboratory animals using protocols approved by the Institutional Animal Care and Use Committee.

\section{Dissociated hippocampal neurons and organotypic slice cultures}

Primary hippocampal neurons from E18 rat embryos were prepared and cultured essentially as described [27]. Most assays for rod formation were performed on polyD-lysine coated 8-well chamber slides or on $15 \mathrm{~mm}$ round coverslips in 24-well plates, with about 10-15,000 neurons per well. Neurons were cultured for 4 days in Neurobasal + B27 supplements, treated on day 4 with rod-inducing reagents and fixed and stained for cofilin rods on day 5 . Hippocampal slice cultures were prepared from P6-P10 Sprague Dawley rat pups as described [50]. Briefly, hippocampi were quickly dissected into filter sterilized ice-cold $\left(4^{\circ} \mathrm{C}\right)$ Gey's Balanced Salt Solution plus $4 \%$ glucose, then sliced to a thickness of $400 \mu \mathrm{m}$ on a McIlwain tissue chopper. For some slices we maintained some entorhinal cortex along with the hippocampus to minimize the degeneration of the perforant pathway [29]. For most slice treatments, 3-6 slices were arranged onto $0.4 \mu \mathrm{m}$ Transwell ${ }^{\circledR}$ Polyester membranes inserted into 6 well culture plates (Corning $\operatorname{Costar}^{\circledR} 3450$, Lowell, MA). Beneath the membrane is added $1.7 \mathrm{~mL}$ of filter sterilized slice culture medium (50 mL horse serum, $50 \mathrm{~mL}$ Hank's Balanced Salt Solution (HBSS), $100 \mathrm{~mL}$ Minimal Essential Medium (MEM), $250 \mu \mathrm{L} 200 \mathrm{mM}$ GlutaMAX, $4 \mathrm{~mL} 25 \%$ glucose, $2 \mathrm{~mL} 1 \mathrm{M}$ 4-(2-hydroxyethyl)-1-piperazine ethane sulfonic acid (HEPES), pH 7.3, $1 \mathrm{~mL}$ 10,000 U/mL PenicillinStreptomycin). Slice culture medium is aspirated and replaced with $1.5 \mathrm{~mL}$ of fresh medium on day 3 and every 2-3 days thereafter or with treatment medium as required. For all experiments slices were cultured for about 10 days in a $95 \%$ air $/ 5 \% \mathrm{CO}_{2}$ incubator at $35.5^{\circ} \mathrm{C}$.

\section{Immunoblotting}

Lyophilized gel filtration fractions of 7PA2 and control culture medium, and aliquots of synthetic $\mathrm{A} \beta$ oligomer preparations were resuspended in $10 \mu \mathrm{L}$ of $2 \mathrm{X}$ sample buffer [51]. For Western blots, samples were electrophoresed on $10-20 \%$ acrylamide gradient Tris-Tricine Ready Gels (Bio-Rad, Hercules, CA). Proteins were transferred onto nitrocellulose $(0.1 \mu \mathrm{m}$; Whatman, Dassel, Germany), the membrane heated to boiling for $10 \mathrm{~min}$ in PBS [52], blocked at room temperature in 1\% BSA, $2 \%$ goat serum in $20 \mathrm{mM}$ Tris- $\mathrm{HCl}, \mathrm{pH} 7.4$, containing $150 \mathrm{mM} \mathrm{NaCl}$ (TBS) for $30 \mathrm{~min}$, and incubated overnight at $4^{\circ} \mathrm{C}$ in primary antibody, $\mathrm{A} \beta$ monoclonal 6E10 (Covance, Dedham, MA; 1:1000 in TBS plus 0.05\% Tween-20 (TBST)).

Blots were incubated in secondary antibodies (DyLight 680 or DyLight 800 conjugates,1:15,000; Thermo Scientific, Rockford, IL) for $45 \mathrm{~min}$ at room temperature. Blots were washed with TBST, imaged with a LI-COR Odyssey Infrared Imaging System, and band intensities quantified using TotalLab software (Nonlinear Dynamics, Newcastle upon Tyne, UK).

$\mathrm{A} \beta$ was quantified in 7PA2 cell culture medium, combined gel filtration fractions of the 7PA2 medium, synthetic $A \beta$ oligomers, and oxidized synthetic $A \beta$ preparations and their gel filtration fractions using a dot blot assay on $0.1 \mu \mathrm{m}$ nitrocellulose with freshly solubilized monomeric synthetic human $\beta$-amyloid peptide $\left(\mathrm{A} \beta_{1-42}\right)$ as a standard. Once samples were applied and dried, the membrane was boiled $10 \mathrm{~min}$ in PBS to expose epitopes in oligomers and then $A \beta$ was detected with 6E10 antibody and spots quantified as monomer equivalents described above for Western blots. The A $\beta$ monomer was shown to be inactive in rod induction but it was often present to various degrees in gel filtration fractions of $A \beta d / t$. Therefore, the amounts of $A \beta d / t$ used in the bioassays were calculated from the total immunoreactive $A \beta$ in the fraction (dot blot assay results) times the percentage of the dimer plus trimer species within each sample quantified from scans of the Western blots described above.

\section{Adenoviral-mediated gene expression}

Adenoviruses for expressing slingshot phosphatase $1 \mathrm{~L}$ (SSH1L), constitutively active LIM kinase (LIMKT508EE), a dominant negative LIM kinase (D470A) and human cofilin-EGFP have all been described previously [53-55]. These were used at a multiplicity of infection (m.o.i.) of 100-300 for infecting dissociated neurons. For infection of organotypic slices, about $10^{7}$ adenoviral 
particles were added directly to the slice culture medium on day 7 and the cultures were returned to the incubator until treated with $\mathrm{A} \beta \mathrm{d} / \mathrm{t}$ or control material on day 8 and fixed for analysis on day 10. Slices cultured on membranes were infected with adenovirus by placing a drop of the adenovirus directly on the slice and adding the excess virus to the culture medium below the slice. One to two hours later the liquid on top of the slice was removed and mixed with the culture medium below the slice. This method gave a higher efficiency of infection than if the virus was only added to the medium below the slice.

\section{Fixation and immunostaining}

Dissociated neurons and slices were fixed for $45 \mathrm{~min}$ or $2 \mathrm{~h}$, respectively, at room temperature in $4 \%$ paraformaldehyde in either cytoskeletal buffer (CBS; 10 mM MES $\mathrm{pH} 6.1,138 \mathrm{mM} \mathrm{KCl}, 3 \mathrm{mM} \mathrm{MgCl} 2,2 \mathrm{mM}$ EGTA pH 7.0, 4\% PEG, $0.32 \mathrm{M}$ sucrose) or PBS adjusted to $\mathrm{pH}$ 7.0, with no apparent differences between buffers. Neurons and slices were methanol $\left(-20^{\circ} \mathrm{C}\right)$ permeabilized for $3 \mathrm{~min}$ (cells) or $10 \mathrm{~min}$ (slices) and blocked in $2 \%$ goat serum/1\% bovine serum albumin in TBS before immunostaining. Primary antibodies include: affinity purified rabbit 1439 IgG to chick $\operatorname{ADF}(2 \mathrm{ng} / \mu \mathrm{L})$, which crossreacts with mammalian ADF and cofilin [56], and protein A purified monoclonal mouse anti-cofilin (MAb22; $10 \mathrm{ng} / \mu \mathrm{L}$ IgG) [57]. Secondary antibodies, all used at 1:450, include Alexa 488 goat anti-rabbit and goat anti-mouse and Alexa 594 goat anti-rabbit and goat anti-mouse (Molecular Probes, Eugene, OR). DAPI (4'-6-Diamidino-2-phenylindole) or Hoechst 33342 were used to stain DNA. Slices on membrane were excised, blocked, immunostained, and mounted on $22 \times 22 \mathrm{~mm}$ cover glasses with ProLong Gold Antifade (Molecular Probes).

\section{Microscopy and Image analysis}

An Olympus IX81 microscope equipped with an ASI piezo stage (Applied Scientific Instrumentation, Eugene, OR), CSU22 spinning disk confocal head (Yokogawa Instruments, Japan), $440 \mathrm{~nm}, 473 \mathrm{~nm}$ and $561 \mathrm{~nm}$ diode lasers, and a $1 \mathrm{~K} \times 1 \mathrm{~K}$ Cascade II EMCCD Camera (Roper Scientific, Tucson, AZ), all integrated and operated by SlideBook software (Intelligent Imaging Innovations, Denver, CO), was used to obtain confocal sections through organotypic slices. The objectives used include 4x Fluorite (0.13 NA), UAPO40X/340W-DIC (1.35 NA), or PlanAPO 60x (1.42 NA). Phase-contrast and nonconfocal fluorescence micrographs were also obtained on a Nikon Diaphot microscope.

MetaMorph v7.03 software (MDS Analytical Technologies, Toronto, Canada) was used for all digital processing. Following time-lapse imaging the slice was scanned for rod formation. All experiments were repeated a minimum of three times. To ascertain the regional distribution of rods, the total number of rods per field was counted using a $60 \mathrm{x}$ oil objective and data from multiple slices were combined onto a schematic of the hippocampus as described previously [29].

\section{Statistics}

Statistical analyses were done with either MATLAB or SPSS v13. Unless otherwise stated, all significance values are at $\mathrm{p}=0.05$ and all error bars are standard deviations. Any post hoc tests are reported.

\section{Results}

\section{$A \beta d / t$ is a potent inducer of cofilin-actin rods}

The total concentration of $A \beta$ species in 7PA2 conditioned medium was previously reported to be $6.4 \mathrm{ng} / \mathrm{mL}$ (1.4 $\mathrm{nM}$ ) based on ELISA [20]. However, oligomers of human A $\beta$ are inefficiently measured by ELISA [58]. Therefore we measured the total human $A \beta$ concentration in several batches of 7PA2 medium using a dot blot assay and obtained the value of $8.3 \pm 0.8 \mathrm{ng} / \mathrm{mL}$ (Additional file 1$)$. The amounts of $A \beta$ dimer/trimer $(A \beta d / t)$ and $A \beta$ monomer $(A \beta m)$ in their respective pooled fractions from gel filtration chromatography (Additional file 1) were also determined directly from dot blot assays to be approximately $1.1 \mathrm{ng} / \mathrm{mL}$ and $3.6 \mathrm{ng} / \mathrm{mL}$, respectively, equal to about $250 \mathrm{pM}$ and $800 \mathrm{pM}$ (expressed as monomer equivalents). This value for $A \beta d / t$ concentration is close to that estimated from the $A \beta d / t$ immunostaining on Western blots after epitope exposure by boiling the membrane [20], and is also quite similar to the concentration of $A \beta d / t$ in 7PA2 medium estimated by Freir et al. [24].

Treatment of cultured dissociated hippocampal neurons with the gel fractionated $\mathrm{A} \beta \mathrm{d} / \mathrm{t}$ at $\sim 250 \mathrm{pM}$ $(1.1 \mathrm{ng} / \mathrm{mL}$; equivalent to the concentration produced in the 7PA2 cell culture medium and referred to as $1 \mathrm{X}$ in other references [20,23]) induced the formation of cofilin-actin rods in many neurons, even more than respond to treatment with $1 \mu \mathrm{M}$ of synthetic human $\mathrm{A} \beta_{1-42}$ oligomers (A $\beta$ syn) (Figure 1). Significant rod induction did not occur in neurons treated with either the $A \beta m$ or fractionated medium prepared from wild type $\mathrm{CHO}$ cells (a control hereafter called non-conditioned (NC) medium). Incubation of $A \beta d / t$ or $A \beta$ syn oligomers with 6E10 anti-A $\beta$ monoclonal antibody (as per [20]) for 15 min prior to neuronal treatment reduced rod formation to control levels, implying it is $A \beta$ and not some other component in 7PA2 medium that is responsible for inducing rods. The percentage of neurons with rods was quantified from each of the cultures treated with fractionated $\mathrm{NC}$ medium, $\mathrm{A} \beta \mathrm{m}, \mathrm{A} \beta \mathrm{d} / \mathrm{t}$, or $\mathrm{A} \beta$ syn oligomers (Figure $1 B$ ). Only $A \beta d / t$ and $A \beta$ syn oligomers induced a 
A
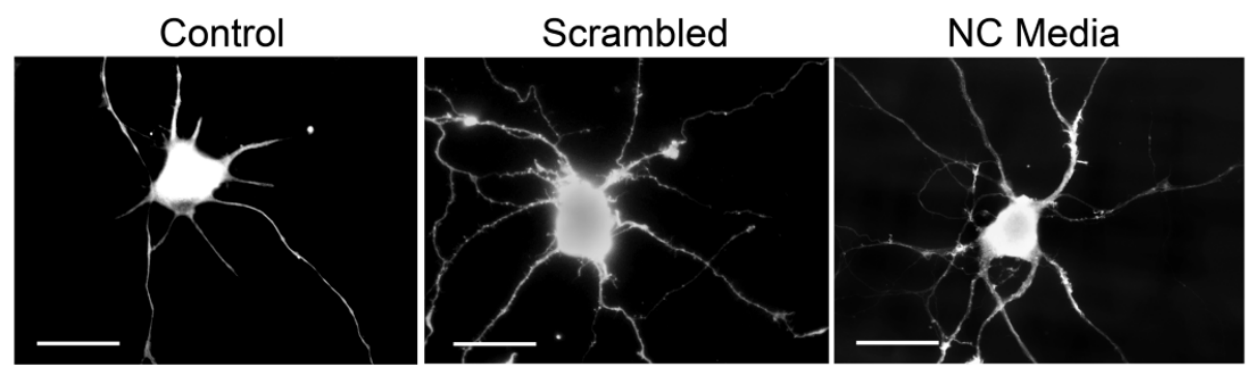

A $\beta$ Monomer

A $\beta$ Dimer/Trimer

Oligomer - $A \beta_{1-42}$
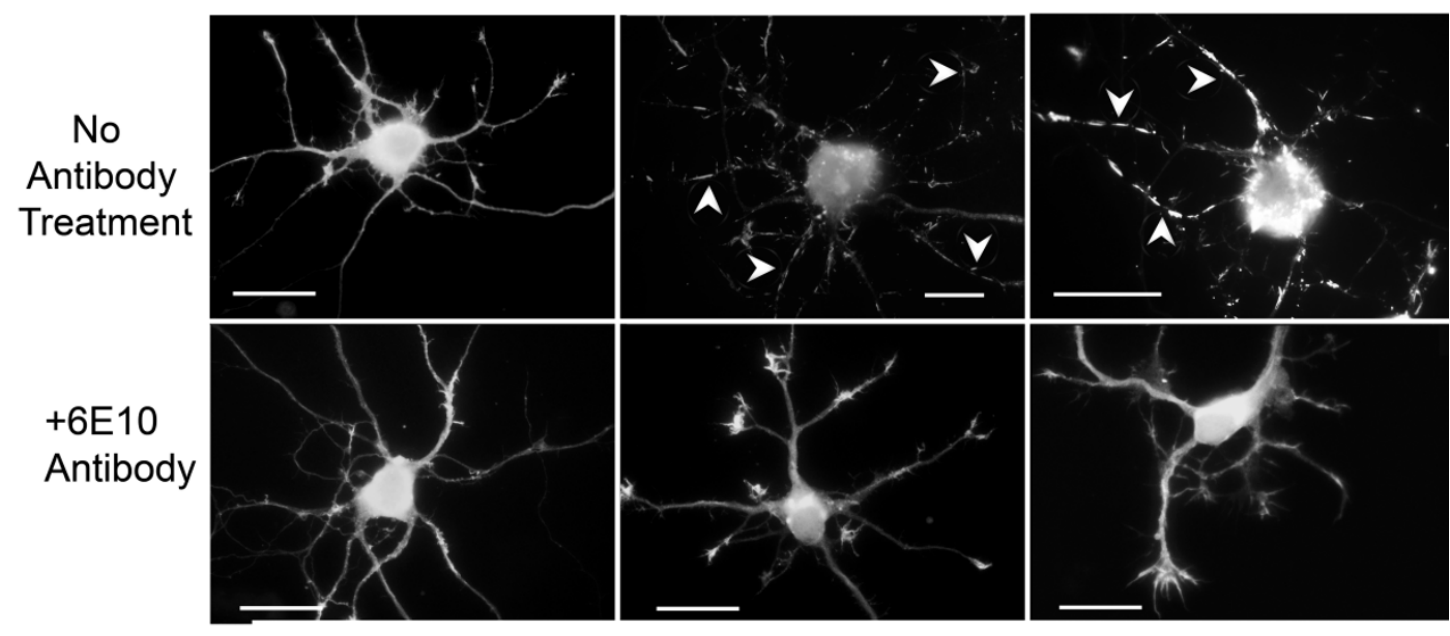

B

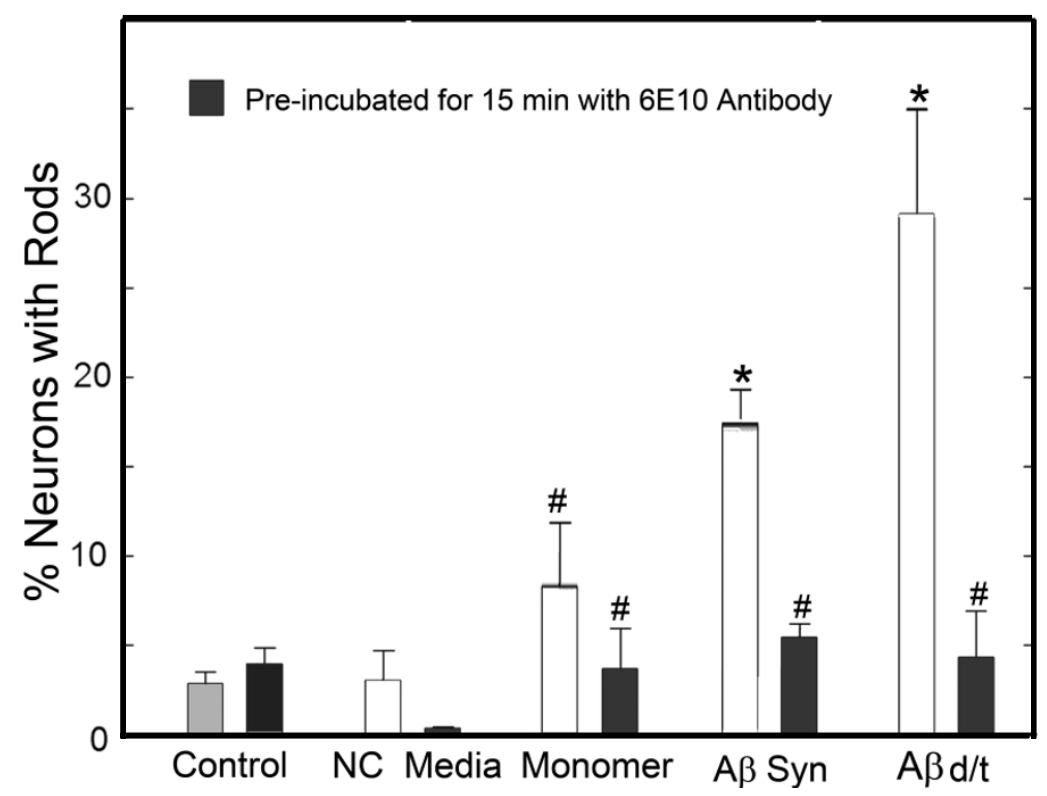

Figure $1 \mathrm{~A} \beta \mathrm{d} / \mathrm{t}$ fraction from 7PA2 cells, but not monomer, induces rods in dissociated hippocampal neurons. Analysis by fluorescence microscopy of dissociated neurons treated with vehicle (control), scrambled AB peptide $(1 \mu \mathrm{M})$, or non-conditioned ( $N C$ media, $d / t$ equivalent fraction), as well as with the monomer and $d / t$ fractions from 7PA2 cell culture medium and $1 \mu \mathrm{M}$ synthetic A $\beta$ oligomers (A 3 syn). (A) Cofilin immunostained fluorescence images of hippocampal neurons showing representative responses with cofilin-actin rods (arrowheads) formed $24 \mathrm{~h}$ after treatment with $A \beta d / t$ and $A \beta$ syn oligomers. Pretreatment of the $A \beta$-fractions with an antibody (6E10) to $A \beta$ eliminates their rod-inducing effects. Bars $=10 \mu \mathrm{m}$. (B) Quantification of the rod forming response showing the neutralizing effects of the $6 \mathrm{E} 10$ antibody and the nonsignificant changes in rod formation by $A \beta$ monomer. $\left({ }^{*}=p=0.01\right.$ compared to control; \# not significantly different from control). 
significant $(\mathrm{p}=0.01)$ increase in the percentage of neurons with rods above control (combined data from untreated and synthetic scrambled $\mathrm{A} \beta$ peptide-treated samples) and NC media (another control). Pretreatment with 6E10 antibody eliminated this increase. Furthermore, the percentage of $\mathrm{A} \beta \mathrm{d} / \mathrm{t}$-treated neurons forming rods (about $30 \%)$ represents a significant $(\mathrm{p}=0.05)$ increase versus treatment with the $1 \mu \mathrm{M}$ A $\beta$ syn oligomers (18\%).

We next compared $A \beta d / t$ to $A \beta$ syn oligomers for dose-response in rod-induction. The gel filtration fractions containing $\mathrm{A} \beta \mathrm{d} / \mathrm{t}$ elute in $50 \mathrm{mM}$ ammonium acetate, $\mathrm{pH} 8.5$ and are freeze dried to remove most of the volatile buffer. However, when reconstituted they cannot be used above a $2.5 \mathrm{X}$ concentration because of increased cell death (release of LDH, data not shown). However, neurons could be treated with the $A \beta d / t$ from $0.1 \mathrm{X}$ to $2 \mathrm{X}$ ( $25 \mathrm{pM}$ to $500 \mathrm{pM}$ ) without any significant cell loss over $48 \mathrm{~h}$. Controls were untreated neurons or neurons treated with NC medium. As shown in Figure 2A, the half-maximal response in terms of numbers of neurons forming rods is achieved with $\sim 0.4 \mathrm{X} \mathrm{A} \beta \mathrm{d} / \mathrm{t}(\sim 100 \mathrm{pM})$ and $\sim 0.7 \mu \mathrm{M}$ A $\beta$ syn oligomers, about a 7000 fold difference. This value compares favorably with the 4000 fold difference obtained using single point comparison at $1 \mathrm{X}$ concentration (250 pM A $\beta d / t$ versus $1 \mu \mathrm{M} A \beta$ syn oligomers), which gives near maximal rod response for each preparation. Furthermore, the maximum percentage of cells with rods is greater with $A \beta d / t$ than with $A \beta$ syn oligomers at all concentrations tested (Figure 2A).
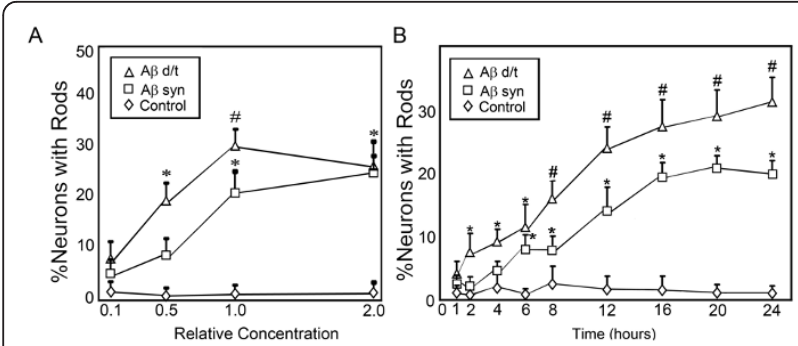

Figure 2 Percent of neurons in dissociated hippocampal cultures containing rods as a function of $A \beta$ form, concentration and time of treatment. (A) Dose-response curves for $A \beta$ syn oligomers and $A \beta d / t$ versus control. The concentrations are expressed in terms of the 7PA2 $\mathrm{CHO}$ cell secreted concentration of $A \beta d / t(1 X=250 \mathrm{pM})$, which was used at $0.1,0.5$ and $2 X$ this value. For the $A \beta$ syn oligomers, the $1 X$ value equals $1.0 \mu \mathrm{M}$. (B) Following treatment with $1 X$ amounts of $A \beta d / t$ or $A \beta$ syn oligomers, neurons were fixed at the times shown and the percent of neurons with rods was quantified. By $2 \mathrm{~h}$ the percent of neurons forming rods in response to $A \beta d / t$ was significant $\left(^{*}\right)$ over controls $(p=0.05)$. The $A \beta$ syn-treated neurons required $6 \mathrm{~h}$ to reach significance over controls. Significance $(\#=p=0.05)$ in the differences between the two $A \beta$ species occurred at $8 \mathrm{~h}$.

\section{Time course of rod formation}

We observed that the percentage of neurons forming rods in response to $1 \mu \mathrm{M} A \beta$ syn oligomers did not increase significantly over untreated samples until $6 \mathrm{~h}$ after addition, as we previously reported [34]. Because the $A \beta d / t$ fraction is more active in rod induction than $A \beta$ syn, we directly compared the time course between these two treatments. The $A \beta d / t$ fraction at $250 \mathrm{pM}$ induces a measurable increase in rods over untreated controls by $1 \mathrm{~h}$ becoming significant $(\mathrm{p}=$ 0.05 ) by $2 \mathrm{~h}$, at which time about $25 \%$ of the maximum response is obtained (Figure $2 \mathrm{~B}$ ). By $8 \mathrm{~h}$ significantly $(\mathrm{p}=0.05)$ more $\mathrm{A} \beta \mathrm{d} / \mathrm{t}$-treated neurons have rods than neurons treated with $1 \mu \mathrm{M} A \beta$ syn oligomers and this difference is maintained through the remaining time studied (24 h).

\section{Oxidation of $A \beta_{1-42}$ generates a rod-inducing SDS-stable dimer}

Oligomerization of human A $\beta$ syn is usually performed on peptide solubilized in DMSO $[44,45]$. These oligomer preparations are noticeably deficient in SDS-stable dimer [59], although SDS-stable trimers and tetramers are present (Figure 3A). Therefore we reasoned that it is likely the increased dimer content that makes the $\mathrm{A} \beta \mathrm{d} / \mathrm{t}$ so much more active in rod-induction than A $\beta$ syn. Oxidation methods to prepare stable tyrosine cross-linked human $A \beta$ dimer have been reported [46]. Human $A \beta$ has a single tyrosine at residue 10 , which is substituted by phenylalanine in rodent $A \beta$ (Figure $3 D$ ). Rodent $A \beta$ (RA $\beta$ ) does not form dimers or other SDS-stable oligomers on its own [46] and does not induce rods even when used at $1 \mu \mathrm{M}$ concentration (Figure $3 \mathrm{~B}$ ). Thus, we addressed the possibility that oxidized human $A \beta$ dimers are contributing to the enhanced rod forming activity of the $A \beta d / t$ fraction. Synthetic human $A \beta_{1-42}$ was incubated with $250 \mu \mathrm{M}$ hydrogen peroxide plus or minus $25 \mu \mathrm{M} \mathrm{CuCl}_{2}$ for 3-5 days (Additional file 2). The presence of the $\mathrm{CuCl}_{2}$ is required to generate the di-tyrosine dimer [46] but not other oxidation products that include dimers (Figure 3A). We compared the rod-inducing ability of the $\mathrm{Cu}^{2+}$ /peroxide oxidized synthetic human $\mathrm{A} \beta$ (OxA $\beta$ syn) to that of the $A \beta d / t$ and the traditionally prepared synthetic human $A \beta$ oligomers (A $\beta$ syn) by performing dose-response curves in cultures of rat hippocampal neurons treated on day 4 and fixed on day 5 (Figure 3C). The presence of $\mathrm{Cu}^{2+} /$ peroxide (Figure 3B) or peroxide alone (data not shown) had no effect on rod formation. It is quite apparent from the curves in Figure $3 \mathrm{C}$ that $\mathrm{A} \beta$ oxidation dramatically enhances its rodinducing activity. The effective concentration for halfmaximal response $\left(\mathrm{EC}_{50}\right)$ is $>7000$ fold different between $\mathrm{A} \beta \operatorname{syn}(3100 \mathrm{ng} / \mathrm{mL}=690 \mathrm{nM})$ and $\mathrm{A} \beta \mathrm{d} / \mathrm{t}(0.4 \mathrm{ng} / \mathrm{mL}=$ $90 \mathrm{pM})$ and $>600$ fold different between $A \beta$ syn and 


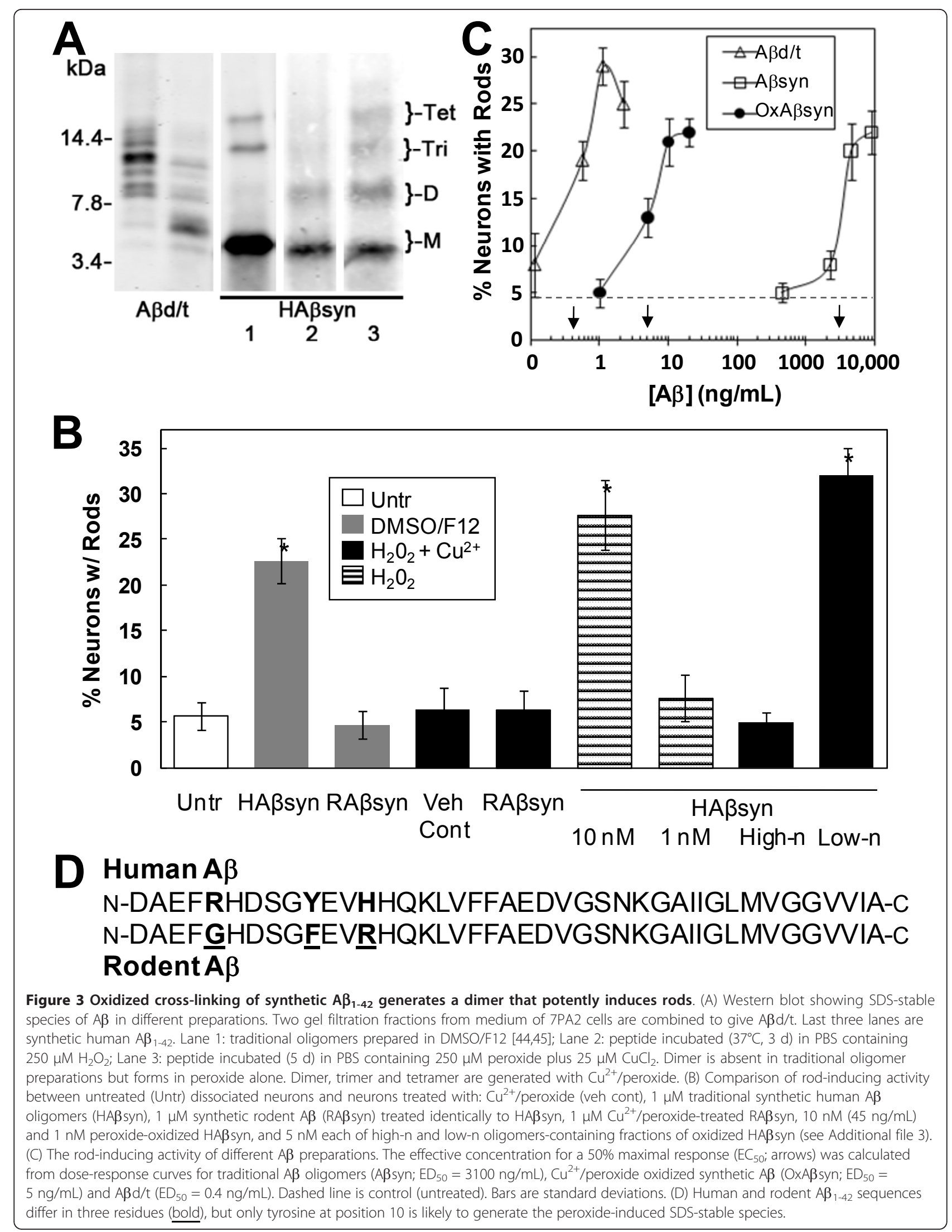


OxAßsyn $(5 \mathrm{ng} / \mathrm{mL}=1.1 \mathrm{nM})$. These concentrations are based on the total $A \beta$ content in the samples tested. If we subtract the amount of monomer remaining in each of the fractions based upon its percentage content from quantified Western blots, there is less than a five-fold difference in the activity of the OxA $\beta$ syn and $A \beta d / t$ samples. In addition, synthetic rodent $A \beta_{1-42}$ ( $R A \beta$ syn) is inactive in rod induction at $1 \mu \mathrm{M}$ when prepared using either standard oligomerizing conditions (DMSO/F12 medium) or $\mathrm{Cu}^{2+}$ /peroxide treatment (Figure 3B), strongly suggesting that oxidation of tyrosine is what drives much, if not all, of the formation of SDS-stable oligomers. Gel filtration of the $\mathrm{Cu}^{2+}$ /peroxide-oxidized human $A \beta$ syn produced two peaks containing $A \beta$ (Additional file 3). Western blots showed that both peaks contained similar mixtures of SDS-stable species (monomer, dimer, trimer and tetramer) with about $25 \%$ eluting near the void volume (high-n species) and the remaining $75 \%$ eluting near the position of 7PA2 cell-secreted $A \beta d / t$ (low-n species), which elutes at the position of dimer, based upon globular protein calibration (Additional file $3)$. The high-n fractions were inactive for rod-inducing activity at $23 \mathrm{ng} / \mathrm{mL}$ ( $5 \mathrm{nM}$ ), whereas the low-n fractions at the same concentration gave as strong a response as has been obtained with any $A \beta$ species (Figure $3 B$ ). Taken together, these results suggest that a variety of oxidized human $A \beta$ dimers can form, that their formation appears to be dependent upon the tyrosine at position 10 , and that their rod-inducing activity may be dramatically impacted by their final aggregation state. The presence of the SDS-stable A $\beta$ dimer in a low-n state appears to be largely responsible for the rod-inducing potency of the $A \beta$.

\section{Stability of the added $A \beta d / t$ fraction}

To determine if the $A \beta d / t$ fraction added to the cultured organotypic slices underwent a change in concentration or altered its SDS-stable $d / t$ form during the incubation, we removed culture medium at the end of experiments (48 h). Human $\mathrm{A} \beta$ was then immunoprecipitated and reanalyzed by SDS-PAGE (Additional file 4). As observed in previous studies [23], there was little change in the concentration of $A \beta d / t$ from what was initially added to the slices.

\section{Regional analysis of $A \beta d / t$-induced rods in hippocampal slices}

The numbers of rods in fields taken from multiple organotypic hippocampal slices that were untreated, treated with NC medium, or treated $48 \mathrm{~h}$ with $250 \mathrm{pM} \mathrm{A} \beta \mathrm{d} / \mathrm{t}$ were mapped onto a matrix grid of the hippocampus using fiduciary points to stretch and fit multiple slice data onto a single summary map as previous described [29]. Similar to the localization of rods in response to
A $\beta$ syn oligomers [29], a treatment also repeated here (data not shown), the $A \beta d / t$-induced rods were mainly localized to the polymorphic hilar region of the dentate gyrus and along the mossy fiber tract into the CA3 region (Figure 4). Furthermore, the numbers of rods per grid square are on average 2-3 fold higher than for the comparable region of the slices treated with A $\beta$ syn oligomer (not shown, but the maximum rods per square on the hot scale in Figure 4A is 60 compared with the maximum of 15 rods per square for synthetic $A \beta$-treated slices previously published [29]). Rod numbers in slices treated with the gel filtration fraction of NC medium were not significantly different from untreated controls and thus data from these slices were combined to make the control panel (Figure 4A). Similar to what was observed in dissociated neurons (Figure 1B) pretreatment of $\mathrm{A} \beta \mathrm{d} / \mathrm{t}$ with $6 \mathrm{E} 10$ antibody reduced the rod numbers in slices to control levels (data not shown).

\section{Dose response curves for rod induction in organotypic slices}

Dose-response curves for rod formation mediated by $A \beta d / t$ versus human $A \beta$ syn oligomers in organotypic slice cultures were produced by quantifying rods per field of view (Figure 5A). This measurement is quite distinct from the data in Figure 2A, because here we are counting total rods and not the percentage of neurons with at least one rod. It should be noted that one field of view, using a $60 x$ oil objective, encompasses the equivalent of about 6-7 matrix grid squares and that rod counts were averaged over the entire slice. Slices treated with the $\mathrm{A} \beta \mathrm{d} / \mathrm{t}$ fraction at $0.1 \mathrm{X}$ (estimated to be $25 \mathrm{pM}$ ) still have a significant $(\mathrm{p}=0.05)$ increase in rods per field over controls. Thus, $25 \mathrm{pM} \mathrm{A} \beta \mathrm{d} / \mathrm{t}$ induces nearly equivalent numbers of rods per field as $500 \mathrm{nM}$ A $\beta$ syn oligomer. The curves are very similar to the doseresponse measured in dissociated neuronal cultures and quantified as percent of neurons with rods (Figure 2A).

\section{Rods induced by $A \beta d / t$ are reversible}

To test if rods induced in organotypic slices by $A \beta d / t$ are reversible, the $A \beta d / t$ was washed out $24 \mathrm{~h}$ after treatment and slices were allowed to recover for $24 \mathrm{~h}$ in control medium. As previously demonstrated for rods induced by human A $\beta$ syn oligomers [29], the majority of rods induced by $250 \mathrm{pM} \mathrm{A} \beta \mathrm{d} / \mathrm{t}$ disappear $24 \mathrm{~h}$ after washout (Figure 5B).

Rods are not apparent in low magnification images of slices, but become apparent when viewed with a $60 \mathrm{x}$ objective, even in single confocal sections (Figure 6A). However, the rod distribution and abundance within the dentate gyrus are more impressive when the confocal image stack is deconvolved and the lowest $20 \%$ intensity of immunstaining is removed by resetting the low 


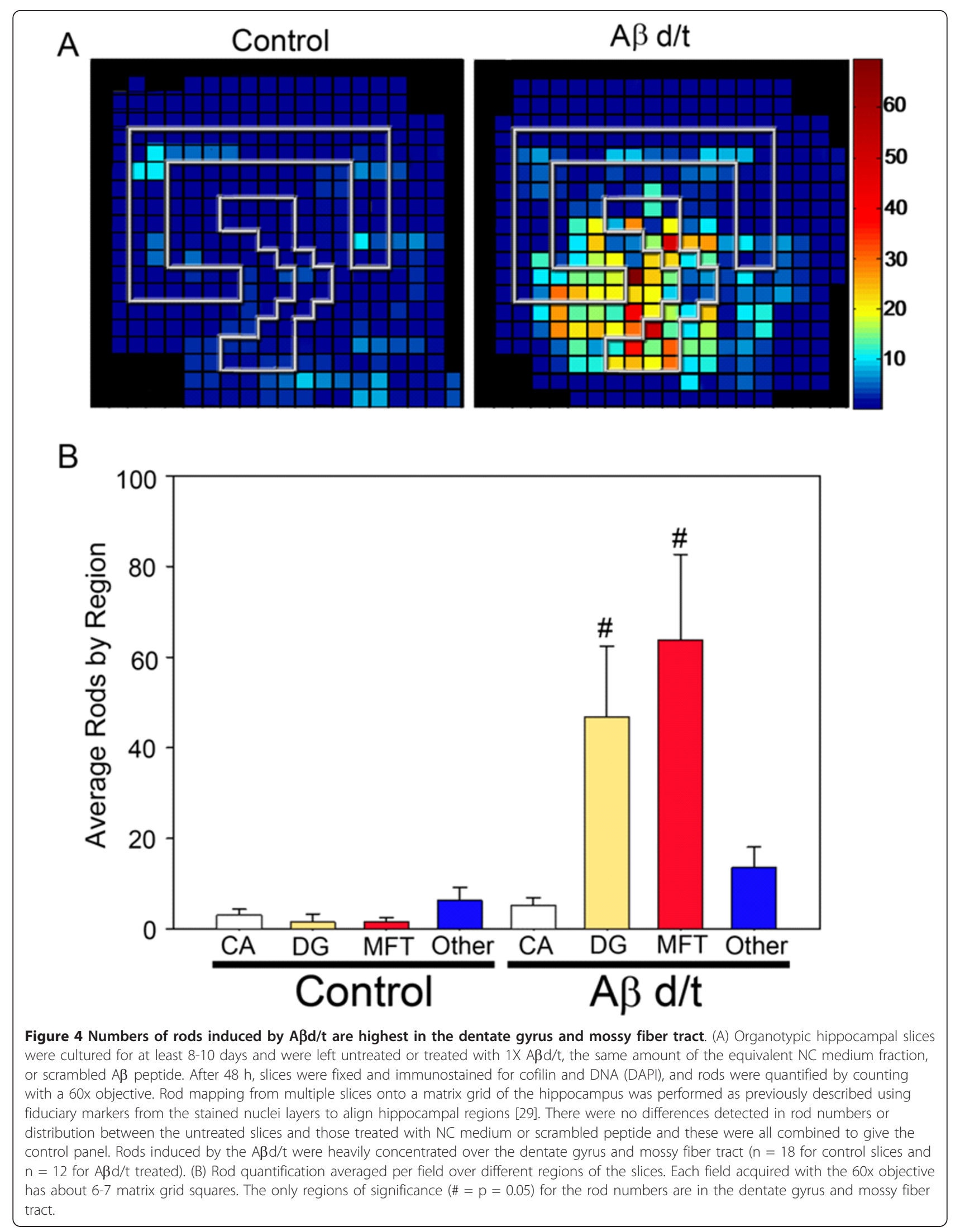




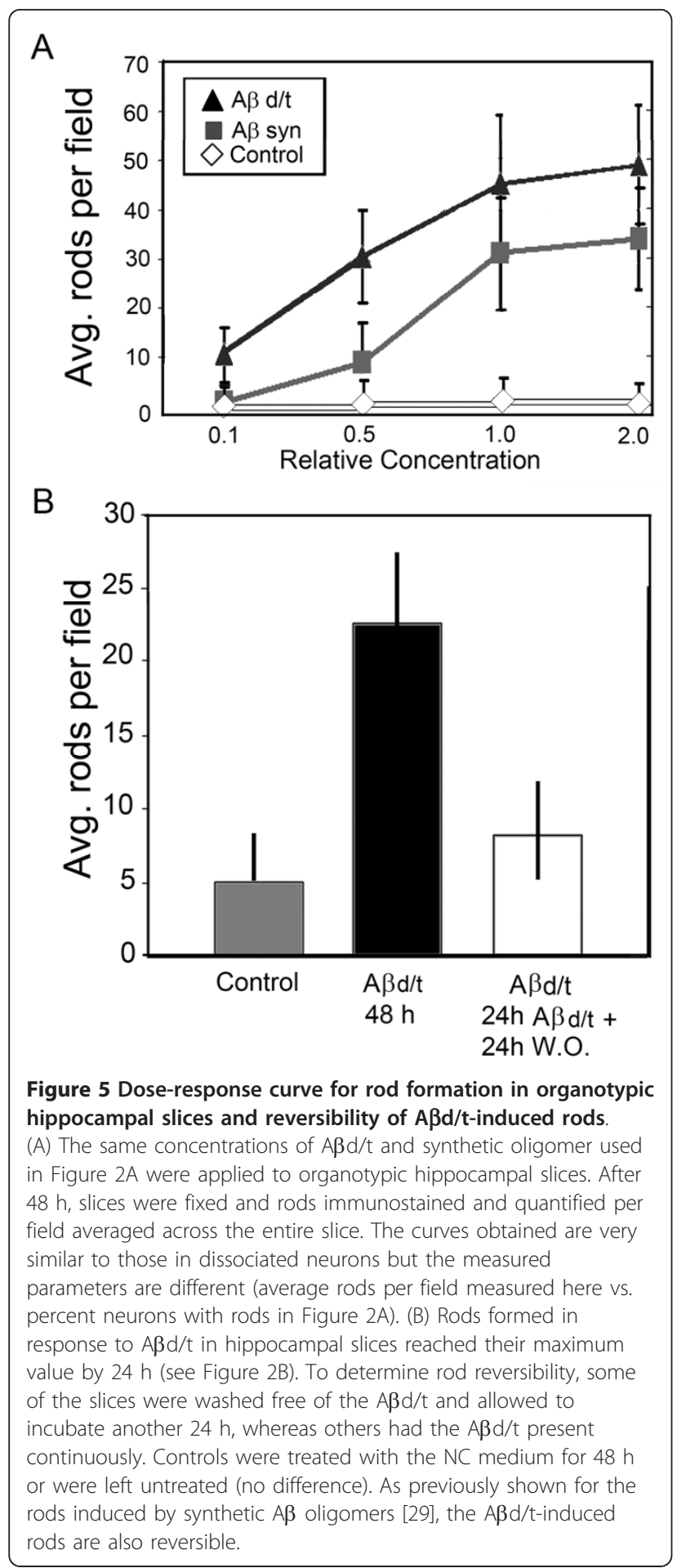

threshold on an image histogram (Figure 6B). Only a few densely stained cofilin aggregates are observed in the $3 \mathrm{D}$ reconstruction of the image stack from control slices whereas rods are abundant throughout the $A \beta d / t$ treated slice.
Modulating cofilin phosphorylation alters rod formation and response to $A \beta d / t$

Since rod formation correlates well with cofilin dephosphorylation, we examined the effects of enhancing or inhibiting cofilin dephosphorylation on rod formation in untreated dissociated neuronal cultures or those treated with $A \beta d / t$. Adenoviral-mediated expression of the cofilin phosphatases, either slingshot (SSH1L) or chronophin (CIN), but not their inactive forms, increases rod formation in the absence of any other rod-inducing treatment whereas the inactive form of slingshot (C393S), and less so CIN (D25A), appears to act in a dominant negative manner by reducing rod formation in cells treated with $250 \mathrm{pM} \mathrm{A} \beta \mathrm{d} / \mathrm{t}$ (Figure 7A). Fluorescent protein co-expression allowed us to identify the infected cells and score these independently from the uninfected cells in the same culture. Greater than 15\% of neurons overexpressing SSH1L formed rods, the most dramatic effect observed, whereas about $8 \%$ of neurons expressing CIN formed rods. Treating neurons expressing these cofilin phosphatases with $A \beta d / t$ significantly $(p=0.05)$ enhanced rod formation above the levels induced by the $A \beta d / t$-treatment alone. A maximum of $38 \%$ of neurons with rods was measured for the SSH-1L expressing neurons treated with $A \beta d / t$ whereas fewer than $10 \%$ of neurons expressing the dominant negative form of SSH1L formed rods when treated with $A \beta d / t$.

Expression of a dominant negative LIM kinase, the major cofilin kinase, did not alter rod formation when expressed on its own, however its presence enhanced the percent of neurons forming rods in response to $\mathrm{A} \beta \mathrm{d} / \mathrm{t}$, although the difference (from $19-20 \%$ to $26 \%$ ) is not significant at $\mathrm{p}=0.05$. Expression of wild type or constitutively active LIMK produced the opposite effect as each significantly $(\mathrm{p}=0.05)$ reduced rod formation in response to $\mathrm{A} \beta \mathrm{d} / \mathrm{t}$ by about $50 \%$ and over $75 \%$ respectively (Figure 7A).

A parallel series of experiments were performed using organotypic slices (Figure 7B). To first estimate the efficiency of transgene expression in the cells of organotypic slices by adenoviral infection, we examined slices at high magnification after adenoviral-mediated expression of a fluorescent protein and staining of nuclei with DAPI. We quantified the number of nuclei with surrounding fluorescent protein expression (Additional file 5) and determined a $>70 \%$ infection efficiency when we used $10^{7}$ infectious particles/slice (based upon a titer of infectious particles per $\mathrm{mL}$ obtained by expression of the viral E2a antigen in infected cells [60]). In organotypic slices, expression of SSH1L or CIN alone did not significantly increase rod formation (quantified as rods per field using the 60x objective) over uninfected controls. In addition, in slices infected and expressing 


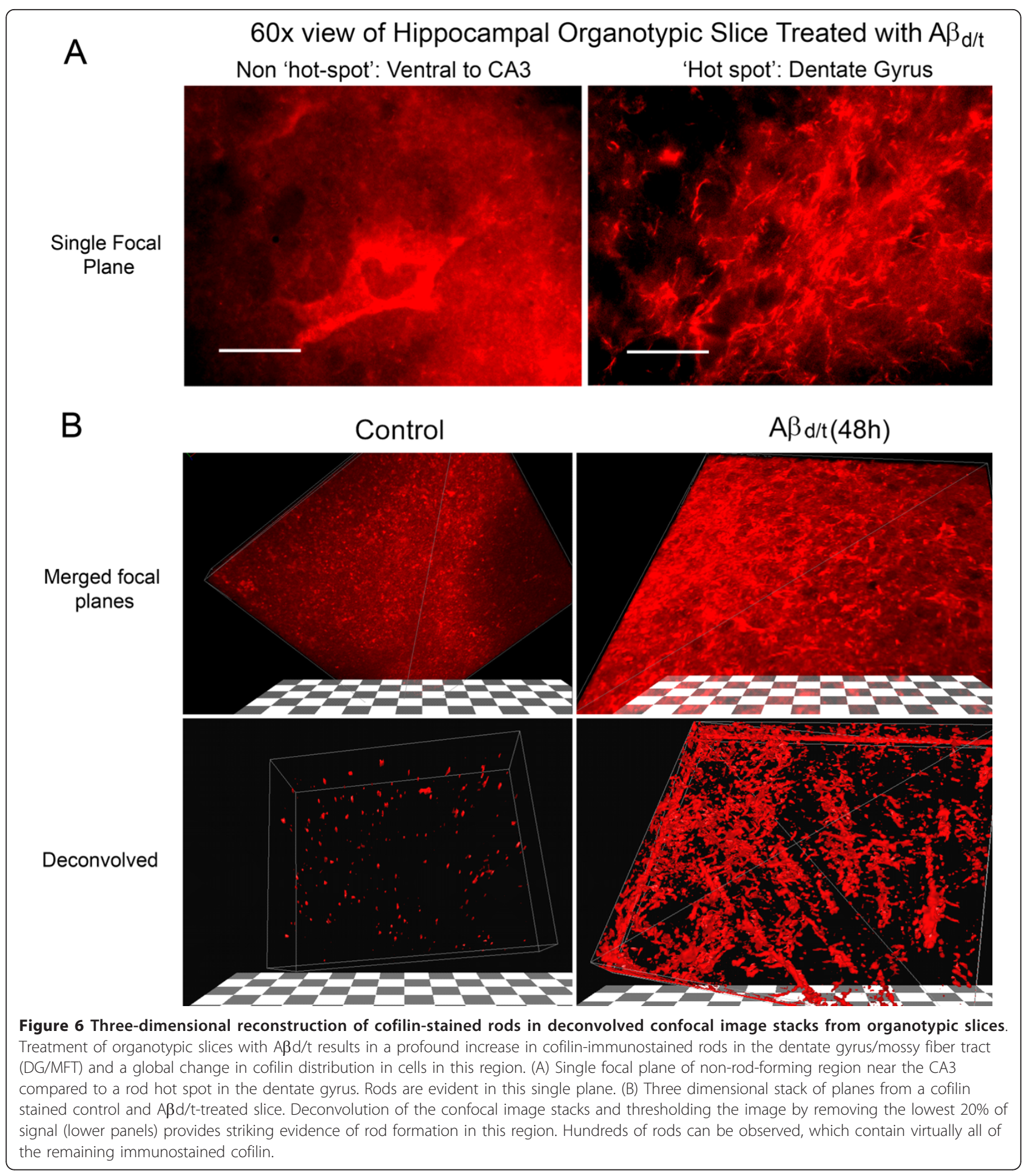

SSH1L or CIN, we did not observe an increase in rod formation in response to $A \beta d / t$ over $A \beta d / t$-treated uninfected controls. However, in slices infected with virus for expressing LIMK wt and LIMK508EE, the average rod number per field in response to $A \beta d / t$ was reduced versus $A \beta d / t$-treated controls (Figure $7 B$ ), similar to what we observed in dissociated cells (Figure 7A). Taken together, these results suggest that cofilin dephosphorylation is necessary and may be sufficient to induce rod formation in many neurons but that the total rod response is enhanced by $A \beta d /$ t-induced stress. 


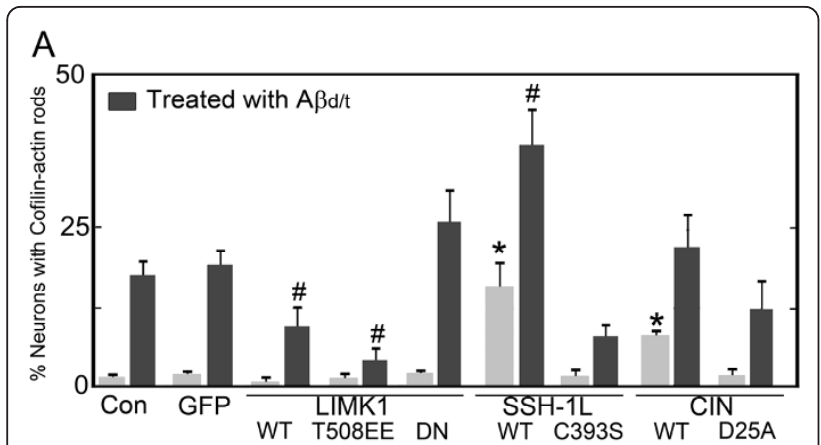

B

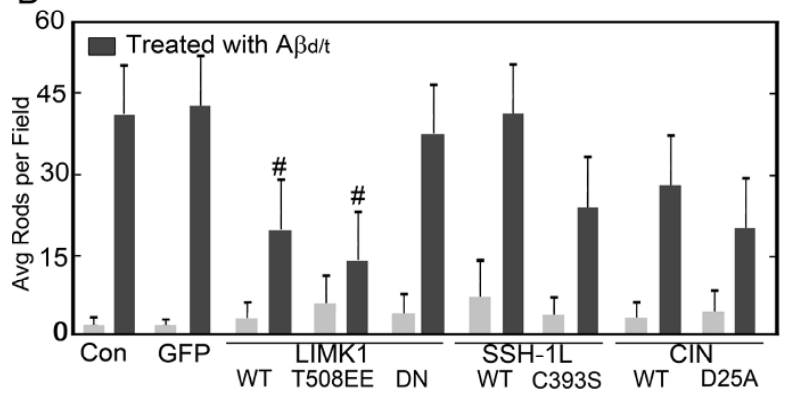

Figure 7 Upstream regulators of cofilin phosphorylation impact the ability of $\mathbf{A} \boldsymbol{\beta d} \mathbf{d} \mathbf{t}$ to induce rods. Rod formation was quantified in (A) dissociated hippocampal neuronal cultures or (B) organotypic hippocampal slices that were uninfected (Con), infected with control adenovirus expressing GFP (GFP) or with adenoviruses expressing various upstream regulators of cofilin phosphorylation. All viruses co-expressed a fluorescent protein marker and only neurons expressing the marker were scored in the dissociated cultures. In slices, infection rates were approximately $70 \%$ (see Additional file 5) and rods per field were quantified (it was not possible in slices to count rods only within infected neurons). Neurons or slices were infected $24 \mathrm{~h}$ prior to treatment with $A \beta \mathrm{d} / \mathrm{t}$ $(1 X)$ and were fixed and analyzed for rod formation $48 \mathrm{~h}$ after $A \beta d / t$ addition. Treatments that enhance cofilin dephosphorylation (the active phosphatases SSH-1L WT and CIN WT) in the dissociated cultures enhance rod formation with or without $A \beta d / t$ treatment $\left(^{*}=\right.$ significant difference from untreated or GFP controls at $p=$ 0.05; \# significantly different from $A \beta d / t$ treated controls, $p=0.05$ ). Treatments that inhibit cofilin dephosphorylation (LIMK1 WT and the active LIMK1T508EE), inhibit rod formation in response to $A \beta d / t$ in both dissociated neuronal cultures and in slices $(n=3)$.

\section{Discussion}

Here we demonstrate that the dimer/trimer fraction of a naturally secreted form of human $A \beta$ is dramatically more potent in inducing cofilin-actin rods than traditionally prepared human $A \beta$ syn oligomers. We estimate $A \beta d / t$ activity is about 4000 fold greater than traditionally prepared human $A \beta$ syn oligomers, but this is based upon an indirect quantification of dimer/trimer concentration using the dot blot to determine total $A \beta$ and gel quantification to estimate the dimer/trimer as a percentage of the total. The maximal activity for $A \beta d / t$ (1.1 $\mathrm{ng} / \mathrm{mL}$ or $\sim 250 \mathrm{pM}$ based on monomer equivalents) is within its estimated physiological concentrations based on the amount extracted from human AD brain $[21,22]$ and the amount detected in cerebrospinal fluid from normal and AD patients [61]. Because the rodinducing activity of the $A \beta d / t$ fraction is neutralized with an $A \beta$ antibody, it is $A \beta$ that appears to be the active rod-inducing component. Furthermore, the lack of significant rod-inducing activity of the $A \beta$ monomer fraction from the 7PA2 medium, even at concentrations three-fold higher than $A \beta d / t$, suggests the SDS-stable dimer is the minimal active unit in promoting cofilinactin rod formation.

It is not known what is responsible for the size distribution of species within the monomer, and SDS-stable low-n oligomer pools. However, naturally occurring human $A \beta$ species modified at their $\mathrm{N}$-terminus to generate both 3-42 and 4-42 isoforms have been reported [62]. The 3-42 isoform with an N-terminal glutamate is capable of forming the pyroglutamate form, which along with 1-40, 1-42 and 4-42 isoforms, are among the most abundant in control, familial AD and sporadic AD brain [62]. Thus mixed oligomers of these different species probably account for the size distribution observed on Western blots.

The nature of the cross-links to generate the SDS-stable species has also been questioned. It was previously shown that tyrosine 10 in the human $A \beta$ sequence can undergo oxidation in the presence of $\mathrm{Cu}^{2+}$ and peroxide to form a specific di-tyrosine cross-link, which did not form in the absence of $\mathrm{Cu}^{2+}\left(\right.$ or $\mathrm{Fe}^{3+}$ ) [46]. However, other peroxide-induced dimers were produced but not characterized, and these presumably could also result in SDS-stable trimer and tetramer species. Rodent $A \beta$ contains no tyrosine (F10 in place of Y10; Figure 3D), is deficient in formation of SDS-stable oligomers [46,63], and does not induce cofilin-actin rods when used at $1 \mu \mathrm{M}$, even after $\mathrm{Cu}^{2+}$ /peroxide treatment (Figure $3 \mathrm{~B}$ ), suggesting that tyrosine oxidized $\mathrm{A} \beta$ and the formation of stable dimers may account for enhanced activity of human $A \beta$. We investigated the biological activity of oxidized human $A \beta$ prepared with peroxide in the presence and absence of copper $[46,47]$. Both oxidized human $A \beta$ preparations had greatly enhanced rod-inducing biological activity, with the one made in the presence of copper being active at a concentration within 10 fold of that of $A \beta d / t$ from 7PA2 cells. However, the enhanced activity of the human $A \beta$ oxidized in the absence of $\mathrm{Cu}^{2+}$ suggests that species of $A \beta$ dimer (or other SDS-stable low-n oligomers) other than those with a di-tyrosine cross-link also contribute to rod-inducing activity.

We assume that the lack of dimers in traditionally prepared oligomers of human $A \beta$ arises from their rapid assembly at the high concentration of human $A \beta$ syn used [64], combined with the antioxidant effects of 
DMSO, which is used to solubilize the peptide $[44,45]$. Our data strongly supports the presence of oxidized human $A \beta$ dimers as contributing to the potent rodinducing activity of the 7PA2 $A \beta d / t$ fractions.

We found that the amount of the $A \beta d / t$ did not change in the medium over $3 \mathrm{~d}$. This is due in part to the fact that rodent $\mathrm{A} \beta$ does not form SDS-stable oligomers and hence the continued secretion of rodent $A \beta$ by the cultured neurons, which is stimulated by the presence of the human $A \beta d / t$ [65], does not contribute to the $A \beta d / t$ pool. It also suggests that neuronal uptake of the $A \beta d / t$, which has been reported [66], occurs at a slow enough rate to not significantly deplete the extracellular pool during the 3 day exposure.

Enhancing cofilin's F-actin binding activity by overexpressing either of the cofilin phosphatases, slingshot or chronophin, enhanced rod formation in dissociated neurons in the absence of $A \beta$-treatment and expression of the cofilin kinase LIMK1 inhibited formation of rods even after $A \beta$-treatment. This result was not unexpected since overexpression of cofilin, especially the nonphosphorylatable cofilin S3A mutant, enhances rod formation [33]. Expression of LIMK1 in organotypic slices reduced $A \beta$-mediated rod formation similar to its effect in dissociated neurons. The expression of cofilin phosphatases in organotypic slice cultures produced no significant increase in rod formation either alone or in response to $A \beta d / t$. Although we find about a $70 \%$ adenoviral infectivity rate of cells in the slices, it is quite likely that the non-neuronal cells infect better than the neurons; thus for some adenoviruses the neuronal infectivity may be low enough that we would have difficulty in obtaining enough infected neurons to observe significant changes in rod formation.

Single infusions into the adult rat brain of either $A \beta$ dimer extracted from human $A D$ brain or $A \beta d / t$ at the identical concentration ( $250 \mathrm{pM})$ used in our studies caused transient memory and learning deficits when measured starting $2 \mathrm{~h}$ after infusion, and completed within a $2 \mathrm{~h}$ maximum time frame [20,21]. Memory and learning deficits disappeared $24 \mathrm{~h}$ after the single infusions. It is worthy to note in this regard that the $A \beta d / t$ fraction induces rods in a statistically significant number of neurons by $2 \mathrm{~h}$ after treatment (about 25\% of the maximal response) and that the $A \beta d / t$ rods are reversible, disappearing by $24 \mathrm{~h}$ after washout. Thus, formation and disappearance of rods in cultured neurons and organotypic slices correlate well with the changes observed in memory and learning in whole animals exposed to a single infusion of $A \beta d / t$.

Nevertheless, the time of rod formation in response to $\mathrm{A} \beta \mathrm{d} / \mathrm{t}$ treatment does not correlate well with acute $A \beta d / t$ effects on slice electrophysiology. Decreased longterm potentiation (LTP) and enhanced long-term depression (LTD) occur within 20 min of treating hippocampal slices in culture either with fractions containing $A \beta d / t$ [23] or with $A \beta$ dimer extracted from human AD brain [21]. This response is more rapid than the $2 \mathrm{~h}$ it takes to obtain a significant increase in rods in organotypic slices exposed to the $A \beta d / t$ fraction. Rod formation has been observed to occur within $10 \mathrm{~min}$ in organotypic slice cultures responding to anoxia or ATPdepletion $[27,29]$. However, the rate of $A \beta d / t$ induced rod formation in organotypic slices maintained in neurobasal/B27 medium may be significantly slower than in acute slices prepared for electrophysiology and maintained in artificial cerebrospinal fluid (aCSF) owing to $0.6 \mu \mathrm{M}$ insulin in the neurobasal/B27 medium not present in aCSF. Insulin helps neurons resist the pathogenic changes in cytoskeletal organization induced by $A \beta$ [67]. Alternatively or in addition, we suspect that cofilin dephosphorylation and altered actin dynamics in response to $A \beta d / t$ is rapid and precedes rod formation in some compartments, such as dendritic spines. Synaptic activity depends directly on cofilin function in regulating actin dynamics and may reflect early changes in plasticity [43,68-70]. Thus, the LTP/LTD response to $A \beta d / t$ could be independent of rod formation yet the result of a localized change in cofilin activity. Significantly, wash out of $\mathrm{A} \beta$ after the electrophysiological changes have occurred did not result in any reversal in the altered LTP/LTD over $2 \mathrm{~h}$. This persistent effect could arise within the organotypic slice from relatively tight binding of the $A \beta d / t$ to specific sites for which some evidence does exist $[23,67]$. Alternatively, rod formation may have occurred by the time washout was initiated and rods could be responsible for the lack of rapid recovery. Rods sequester most of the cofilin $[27,33]$ needed to re-establish the balance in spine actin dynamics [9] and their formation would resist rapid recoveries of the spine cofilin pool.

The most sensitive pool of neurons forming rods in response to both synthetic $A \beta$ oligomers and $A \beta d / t$ are those within the polymorphic/hilar region of the dentate gyrus along the mossy fiber tract into the CA3. The dentate gyrus is considered to play a central role in associative memory [71]. Its major input comes via the perforant pathway with axons representing approximately one million excitatory entorhinal neurons from layer II. These axons end preferentially within the outer two thirds of the superficial molecular layer, mainly on the apical dendrites of the granule cells, but also on dendrites of interneurons [35]. Cholinergic neurons from the basal forebrain provide another important afferent input, and also synapse with neurons of the dentate gyrus inner molecular layer. The CA3 pyramidal cells receive the granule cell output via the mossy fibers (granule cell axons) and aid in pattern completion [72]. 
Because of its central role in associative memory, the dentate gyrus has been extensively studied in AD brain [35]. There is an early loss of synapses (48\% decrease in synapse to neuron ratio) before significant loss of neurons $[42,73,74]$. Based upon the degree of immunofluorescence labeling for the synaptic marker synaptophysin, there is a direct correlation of synaptic loss during $A D$ progression. Early, mild and severe AD cases are accompanied by a decline in synaptophysin staining of about 25,45 and $65 \%$, respectively, in the outer and middle third of the molecular layer, with little to no loss in the inner third [75]. Injection of single doses of $A \beta d$ / $\mathrm{t}$-containing medium into brains of adult rats also leads to defects in associative memory and to memory consolidation with a striking inhibition of the synaptic increases that occur during memory consolidation in the dentate gyrus [24].

\section{Conclusions}

We have demonstrated that the most synaptotoxic species of $A \beta$ yet identified, that fraction of cell secreted $A \beta$ containing SDS-stable dimers and trimers at subnanomolar concentration, is able to induce cofilin-actin rods in neurites of hippocampal neurons. Synthetic human but not rodent $A \beta$ can be converted into this more highly active rod-inducing form by oxidative conditions, suggesting that it is tyrosine oxidation products that are the most active species. Cofilin-actin rod formation in response to $A \beta d / t$ is most prominent within the dentate gyrus and mossy fiber tract of the hippocampus. Because rods block transport and cause distal atrophy of the neurites in which they form without death of the neuron $[27,39]$, they represent a likely mechanism to explain the synaptic loss associated with early stages of $\mathrm{AD}$ and thus represent a novel target for therapeutic intervention.

\section{Additional material}

Additional file 1: Preparation and quantification of $A \beta d / t$. (A) $A \beta$

Western blot (6E10 antibody) of gel filtration fractions from a single Superdex 75 (10/30 HR) column run at a flow rate of $0.5 \mathrm{~mL} / \mathrm{min}$ and loaded with $1 \mathrm{~mL}$ of a 10X concentrate of 7PA2 cell conditioned (16 h) DMEM medium $[20,43]$. (B, C) Dot blot standard curve for quantification of $A \beta$ monomer equivalents in the 7PA2 culture medium and final $A \beta d / t$ fraction.

Additional file 2: Western blot showing time course of oxidative changes in synthetic human $A \beta_{1-42}$ incubated under different conditions to generate SDS-stable dimers and higher oligomers. Synthetic human A $\beta$ was dissolved to $5 \mu \mathrm{M}$ directly into PBS alone or PBS containing $250 \mu \mathrm{M}$ hydrogen peroxide, $25 \mu \mathrm{M} \mathrm{CuCl}_{2}$, or peroxide plus $\mathrm{CuCl}_{2}$, incubated at $37^{\circ} \mathrm{C}$, and aliquots were removed at 1 day intervals for the times shown to examine the species present by Western blotting. After transfer, the blotting membrane was heated to boiling to expose the epitopes for detection with the 6E10 antibody.

Additional file 3: Western blot showing fractions of gel filtration column of $\mathrm{Cu}^{2+}$-peroxide-treated synthetic human $A \beta_{1-42}$. $A \beta$
Western blot (6E10 antibody) of gel filtration fractions from a single Superdex75 (10/30 HR) column run at a flow rate of $0.5 \mathrm{~mL} / \mathrm{min}$ and loaded with $1 \mathrm{~mL}$ of the $\mathrm{Cu}^{2+}$-peroxide-treated synthetic human $\mathrm{A} \beta_{1-42}$ after 5 days of incubation. Fraction volumes are $0.5 \mathrm{~mL}$ and column void volume is about $6.5 \mathrm{~mL}$. Two peaks of $A \beta$ elute, one at the void volume and the second near the peak of the $A \beta \mathrm{d} / \mathrm{t}$ elution (about $12 \mathrm{ml}$ ). Upper plot shows the column calibration with points for chicken egg albumin (44 kDa), horse myoglobin (17 kDa) and vitamin B12 (1.35 kDa). Combined fractions of the high-n and low-n $A \beta$ species used for the rod-induction assay in Figure $3 \mathrm{~B}$ are underlined.

Additional file 4: The $A \beta d / t$ fraction remains stable for $48 \mathrm{~h}$ when incubated with neurons. Immunoprecipitates from 7PA2 medium (IP positive controls on left) and from neuronal culture medium $48 \mathrm{~h}$ after treatment with $A \beta d / t$, the equivalent fraction from NC medium, or the monomer fraction. The load volume on the right is equivalent to $0.4 \mathrm{~mL}$ of starting 7PA2 medium and the dimer/trimer bands are slightly less than what is contained in the $0.5 \mathrm{~mL}$ of starting medium showing that the $d / t$ fraction is stable over the $48 \mathrm{~h}$ of culture.

Additional file 5: Measurement of adenoviral infection efficiency of cells in organotypic slices. (A) Low magnification (4x objective) images of a hippocampal organotypic slice stained with DAPI, immunostained for cofilin, and imaged for GFP-expression after infection with adenovirus expressing GFP behind a CMV promoter. (B) Infection efficiency in organotypic slices, measured by the numbers of cells showing GFP fluorescence around a DAPI stained nucleus. Between $70-75 \%$ of the cells so examined were positive for GFP. (C) This panel was assembled to illustrate how we determined the percentage of infected cells. One region from a confocal plane of an image stack (60x objective) is shown. The areas surrounding nuclei within this plane were examined for GFP expression, which had to be above a threshold level to be counted as positive. Nuclei were often above or below the optical section containing the GFP and we used a $Z$ stack to obtain the most accurate counts. Hundreds of nuclei across different areas were examined to obtain the infection efficiency.

\section{Acknowledgements and funding}

The authors gratefully acknowledge funding from the NIH National Institute of Neurological Disorders and Stroke (NS40371 to J.R.B., NS43115 to RCD, MTM, and JRB) and a Core Infrastructure Grant for Microscope Imaging from Colorado State University. We are grateful for both technical and intellectual input from Chi Pak and Alisa Shaw and valuable discussions from these same individuals and from Barbara Bernstein, Kevin Flynn, and O'Neil Wiggan.

\section{Author details}

${ }^{1}$ Department of Biochemistry and Molecular Biology, Colorado State University, Fort Collins, CO 80523-1870, USA. ${ }^{2}$ Center for Neurologic Diseases, Brigham and Women's Hospital and Harvard Medical School, 77 Avenue Louis Pasteur, Boston, Massachusetts 02115, USA. ${ }^{3}$ Department of Neurology and Neurological Sciences, Stanford University School of Medicine, Stanford, CA 94305, USA.

\section{Authors' contributions}

This project was conceived by MTM and JRB with input on experimental design and reagents from DJS and MP. RCD took over the project shortly after its initiation and, with technical assistance from LSM, completed most of the neuronal culture and brain slice studies using $A \beta d / t$ provided by DJS and characterized by MP. ITM took over $A \beta d / t$ purification performed the studies on $A \beta$ characterization, including the oxidation and activity assays of synthetic $A \beta$. The manuscript was written primarily by JRB with significant input from MTM and other co-authors. All authors have read and approved the final manuscript.

\section{Competing interests}

The authors have no competing interests. 


\section{References}

1. Glenner GG, Wong CW: Alzheimer's disease: initial report of the purification and characterization of a novel cerebrovascular amyloid protein. Biochem Biophys Res Commun 1984, 120:885-890.

2. Hardy J, Selkoe DJ: The amyloid hypothesis of Alzheimer's disease: progress and problems on the road to therapeutics. Science 2002, 297:353-356.

3. Mattson MP: Pathways towards and away from Alzheimer's disease. Nature 2004, 430:631-639.

4. Price DL, Sisodia SS, Gandy SE: Amyloid beta amyloidosis in Alzheimer's disease. Curr Opin Neurol 1995, 8:268-274.

5. Sisodia SS, Price DL: Role of the beta-amyloid protein in Alzheimer's disease. FASEB J 1995, 9:366-370.

6. Tanzi RE, Bertram L: Twenty years of the Alzheimer's disease amyloid hypothesis: a genetic perspective. Cell 2005, 120:545-555.

7. Chartier-HarlinM C, Crawford F, Hamandi K, Mullan M, Goate A, Hardy J, Backhovens H, Martin JJ, Broeckhoven CV: Screening for the beta-amyloid precursor protein mutation (APP717: Val_-lle) in extended pedigrees with early onset Alzheimer's disease. Neurosci Lett 1991, 129:134-135.

8. Chartier-Harlin MC, Crawford F, Houlden H, Warren A, Hughes D, Fidani L, Goate A, Rossor M, Roques P, Hardy J, Mullan M: Early-onset Alzheimer's disease caused by mutations at codon 717 of the beta-amyloid precursor protein gene. Nature 1991, 353:844-846.

9. Goate A, Chartier-Harlin MC, Mullan M, Brown J, Crawford F, Fidani L, Giuffra L, Haynes A, Irving N, James L, Mant R, Newton P, Rooke R, Roquis P, Talbot C, Pericak-Vance M, Roses A, Williamson R, Rossor M, Owen M, Owen M, Hardy J: Segregation of a missense mutation in the amyloid precursor protein gene with familial Alzheimer's disease. Nature 1991, 349:704-706.

10. Murrell J, Farlow M, Ghetti B, Benson MD: A mutation in the amyloid precursor protein associated with hereditary Alzheimer's disease. Science 1991, 254:97-99.

11. Deshpande A, Mina E, Glabe C, Busciglio J: Different conformations of amyloid beta induce neurotoxicity by distinct mechanisms in human cortical neurons. J. Neurosci 2006, 26:6011-6018.

12. Maloney MT, Bamburg JR: Cofilin-mediated neurodegeneration in Alzheimer's disease and other amyloidopathies. Mol Neurobiol 2007, 35:21-44.

13. Heredia L, Helguera P, de Olmos S, Kedikian G, Sola VF, LaFerla F, Staufenbiel M, de Olmos J, Busciglio J, Caceres A, Lorenzo A: Phosphorylation of actin-depolymerizing factor/cofilin by LIM-kinase mediates amyloid beta-induced degeneration: a potential mechanism of neuronal dystrophy in Alzheimer's disease. J Neurosci 2006, 26:6533-6542.

14. Krafft GA, Klein WL: ADDLs and the signaling web that leads to Alzheimer's disease. Neuropharmacology 2010, 59:230-242.

15. Lambert MP, Barlow AK, Chromy BA, Edwards C, Freed R, Liosatos M, Morgan TE, Rozovsky I, Trommer B, Viola K, Zhang C, Finch CE, Krafft GA, Klein WL: Diffusible, nonfibrillar ligands derived from Abeta1-42 are potent central nervous system neurotoxins. Proc Natl Acad Sci USA 1998, 95:6448-6453

16. Wang HW, Pasternak JF, Kuo H, Ristic H, Lambert MP, Chromy B, Viola KL, Klein WL, Stine WB, Krafft GA, Trommer BL: Soluble oligomers of beta amyloid (1-42) inhibit long-term potentiation but not long-term depression in rat dentate gyrus. Brain Res 2002, 924:133-140.

17. Ohno M, Chang L, Tseng W, Oakley H, Citron M, Klein WL, Vassar R, Disterhoft JF: Temporal memory deficits in Alzheimer's mouse models: rescue by genetic deletion of BACE1. Eur J Neurosci 2006, 23:251-260.

18. Kimura R, Devi L, Ohno M: Partial reduction of BACE1 improves synaptic plasticity, recent and remote memories in Alzheimer's disease transgenic mice. J Neurochem 2010, 113:248-261.

19. Walsh DM, Klyubin I, Fadeeva JV, Cullen WK, Anwyl R, Wolfe MS, Rowan MJ, Selkoe DJ: Naturally secreted oligomers of amyloid beta protein potently inhibit hippocampal long-term potentiation in vivo. Nature 2002 416:535-539.

20. Cleary JP, Walsh DM, Hofmeister JJ, Shankar GM, Kuskowski MA, Selkoe DJ, Ashe $\mathrm{KH}$ : Natural oligomers of the amyloid-beta protein specifically disrupt cognitive function. Nat Neurosci 2005, 8:79-84.

21. Shankar GM, Li S, Mehta TH, Garcia-Munoz A, Shepardson NE, Smith I, Brett FM, Farrell MA, Rowan MJ, Lemere CA, Regan CM, Walsh DM, Sabatini BL, Selkoe DJ: Amyloid-beta protein dimers isolated directly from
Alzheimer's brains impair synaptic plasticity and memory. Nat Med 2008, 14:837-842.

22. McDonald JM, Savva GM, Brayne C, Welzel AT, Forster G, Shankar GM, Selkoe DJ, Ince PG, Walsh DM, Medical Research Council Cognitive Function and Ageing Study: The presence of sodium dodecyl sulphate-stable Abeta dimers is strongly associated with Alzheimer-type dementia. Brain 2010, 133:1328-1341.

23. Townsend M, Shankar GM, Mehta T, Walsh DM, Selkoe DJ: Effects of secreted oligomers of amyloid beta-protein on hippocampal synaptic plasticity: a potent role for trimers. J Physiol 2006, 572:477-492.

24. Freir DB, Fedriani R, Scully D, Smith IM, Selkoe DJ, Walsh DM, Regan CM: A $\beta$ oligomers inhibit synapse remodelling necessary for memory consolidation. Neurobiol Aging 2010, 2010 Jan 22.

25. Reed MN, Hofmeister JJ, Jungbauer L, Weizel AT, Yu C, Sherman MA, Lesne S, Ladu MJ, Walsh DM, Ashe KH, Cleary JP: Cognitive effects of cellderived and synthetically derived Abeta oligomers. Neurobiol Aging 2009, 2009 Dec 21.

26. Bamburg JR, Bloom GS: Cytoskeletal pathologies of Alzheimer disease. Cell Motil Cytoskel 2009, 66:635-649.

27. Minamide LS, Striegl AM, Boyle JA, Meberg PJ, Bamburg JR: Neurodegenerative stimuli induce persistent ADF/cofilin-actin rods that disrupt distal neurite function. Nat Cell Biol 2000, 2:628-636.

28. Huang TY, Minamide LS, Bamburg JR, Bokoch GM: Chronophin mediates an ATP-sensing mechanism of cofilin dephosphorylation and neuronal cofilin-actin rod formation. Dev Cell 2008, 15:691-703.

29. Davis RC, Maloney MT, Minamide LS, Flynn KC, Stonebraker MA, Bamburg JR: Mapping cofilin-actin rods in stressed hippocampal slices and the role of cdc42 in amyloid $\beta$-induced rods. J Alz Dis 2009, 18:35-50.

30. Bamburg JR, Bernstein BW, Davis RC, Flynn KC, Goldsbury C, Jensen JR, Maloney MT, Marsden IT, Minamide LS, Pak CW, Shaw AE, Whiteman IT, Wiggan O: ADF/cofilin-actin rods in neurodegenerative diseases. Curr Alzheimer Res 2010, 7:241-250.

31. Kim JS, Huang TY, Bokoch GM: Reactive oxygen species (ROS) regulate a slingshot-cofilin activation pathway. Mol Biol Cell 2009, 20:2650-2660.

32. Homma K, Niino $Y$, Hotta $K$, Oka $K: \mathrm{Ca}(2+)$ influx through $\mathrm{P} 2 \mathrm{X}$ receptors induces actin cytoskeleton reorganization by the formation of cofilin rods in neurites. Mol Cell Neurosci 2008, 37:261-270.

33. Bernstein BW, Chen H, Boyle JA, Bamburg JR: Formation of actin-ADF/ cofilin rods transiently retards decline of mitochondri8al potential and ATP in stressed neurons. Am J Physiol Cell Physiol 2006, 291:C828-C839.

34. Maloney MT, Minamide LS, Kinley AW, Boyle JA, Bamburg JR: Betasecretase-cleaved amyloid precursor protein accumulates at actin inclusions induced in neurons by stress or amyloid beta: a feedforward mechanism for Alzheimer's disease. J Neurosci 2005, 25:11313-11321.

35. Ohm TG: The dentate gyrus in Alzheimer's disease. Prog Brain Res 2007, 163:723-740.

36. Minamide LS, Maiti S, Boyle JA, Davis RC, Coppinger JA, Bao Y, Huang TY, Yates J, Bokoch GM, Bamburg JR: Isolation and characterization of cofilinactin rods from stressed cells. J Biol Chem 2010, 285:5450-5460.

37. Fulga TA, Elson-Schwab I, Khurana V, Steinhilb ML, Spires TL, Hyman BT, Feany MB: Abnormal bundling and accumulation of F-actin mediates tau-induced neuronal degeneration in vivo. Nat Cell Biol 2007, 9:139-148.

38. Whiteman IT, Gervasio OL, Cullen KM, Guillemin GJ, Jeong EV, Witting PK, Antao ST, Minamide LS, Bamburg JR, Goldsbury C: Activated ADF/cofilin sequesters phosphorylated microtubule associated protein during assembly of Alzheimer-like neuronal cytoskeletal striations. J Neurosci 2009, 29:12994-13005.

39. Jang DH, Han JH, Lee SH, Lee YS, Park H, Lee SH, Kim H, Kaang BK: Cofilin expression induces cofilin-actin rod formation and disrupts synaptic structure and function in Aplysia synapses. Proc Natl Acad Sci USA 2005, 102:16072-16077.

40. Stokin GB, Goldstein LS: Axonal transport and Alzheimer's disease. Annu Rev Biochem 2006, 75:607-627.

41. Velasco ME, Smith MA, Siedlak SL, Nunomura A, Perry G: Striation is the characteristic abnormality in Alzheimer disease. Brain Res 1998, 813:329-333

42. Davies CA, Mann DMA, Sumpter PQ, Yates PO: A quantitative morphometric analysis of the neuronal and synaptic content of the frontal and temporal cortex in patient with Alzheimer's disease. $J$ Neurol Sci 1987, 78:151-164. 
43. Shankar GM, Bloodgood BL, Townsend M, Walsh DM, Selkoe DJ, Sabatini BL: Natural oligomers of the Alzheimer amyloid-beta protein induce reversible synapse loss by modulating an NMDA-type glutamate receptor-dependent signaling pathway. J Neurosci 2007, 27:2866-2875.

44. Dahlgren KN, Manelli AM, Stine WB Jr, Baker LK, Krafft GA, LaDu MJ: Oligomeric and fibrillar species of amyloid-beta peptides differentially affect neuronal viability. J Biol Chem 2002, 277:32046-32053.

45. Stine WB Jr, Dahlgren KN, Krafft GA, LaDu MJ: In vitro characterization of conditions for amyloid-beta peptide oligomerization and fibrillogenesis. J Biol Chem 2003, 278:11612-11622.

46. Atwood CS, Perry G, Zeng H, Kato $Y$, Jones WD, Ling KQ, Huang X, Moir RD, Wang D, Sayre LM, Smith M, Chen SG, Bush Al: Copper mediates dityrosine cross-linking of Alzheimer's amyloid-beta. Biochemistry 2004, 43:560-568.

47. Barnham KJ, Haeffner F, Ciccotosto GD, Curtain CC, Tew D, Mavros C, Beyreuther K, Carrington D, Masters CL, Cherny RA, Cappai R, Bush Al: Tyrosine gated electron transfer is key to the toxic mechanism of Alzheimer's disease beta-amyloid. FASEB J 2004, 18:1427-1429.

48. Smith DG, Cappai R, Barnham KJ: The redox chemistry of the Alzheimer's disease amyloid $\beta$ peptide. Biocheim Biophys Acta 2007, 1768:1976-1990.

49. Mattson MP, Kater SB: Isolated hippocampal neurons in cryopreserved long-term cultures: development of neuroarchitecture and sensitivity to NMDA. Int J Dev Neurosci 1988, 6:439-452.

50. Stoppini L, Buchs PA, Muller D: A simple method for organotypic cultures of nervous tissue. J Neurosci Methods 1991, 37:173-182.

51. Laemmli UK: Cleavage of structural proteins during the assembly of the head of bacteriophage T4. Nature 1970, 227:680-685.

52. Shankar GM, Welzel AT, McDonald JM, Selkoe DJ, Walsh DM: Isolation of low-n amyloid $\beta$-protein oligomers from cultured cells, CSF, and brain. Methods Mol Biol 2011, 670:33-44

53. Dawe HR, Minamide LS, Bamburg JR, Cramer LP: ADF/cofilin controls cell polarity during fibroblast migration. Curr Biol 2003, 13:252-257.

54. Soosairajah J, Maiti S, Wiggan O, Sarmiere P, Moussi N, Sarcevic B, Sampath R, Bamburg JR, Bernard O: Interplay between componets of a novel LIM kinase-slingshot phosphatase complex regulates cofilin. EMBO J 2005, 24:473-486.

55. Garvalov BK, Flynn KC, Neukirchen D, Meyn L, Teusch N, Wu X, Brakebusch C, Bamburg JR, Bradke F: Cdc42 regulates cofilin during the establishment of neuronal polarity. J Neurosci 2007, 27:13117-13129.

56. Shaw AE, Minamide LS, Bill CL, Funk JD, Maiti S, Bamburg JR: Crossreactivity of antibodies to actin- depolymerizing factor/cofilin family proteins and identification of the major epitope recognized by a mammalian actin-depolymerizing factor/cofilin antibody. Electrophoresis 2004, 25:2611-2620.

57. Abe H, Ohshima S, Obinata T: A cofilin-like protein is involved in the regulation of actin assembly in developing skeletal muscle. J Biochem 1989, 106:696-702.

58. Stenh C, Englund H, Lord A, Johansson AS, Almeida CG, Gellerfors P, Greengard P, Gouras GK, Lannfelt L, Nilsson LN: Amyloid beta oligomers are inefficiently measured by enzyme-linked immunosorbant assay. Ann Neurol 2005, 58:147-50

59. Puzzo D, Privitera L, Leznik E, Fa M, Staniszewski A, Palmeri A, Arancio O: Picomolar amyloid-beta positively modulates synaptic plasticity and memory in hippocampus. J Neurosci 2008, 28:14537-14545.

60. Minamide LS, Shaw AE, Sarmiere PD, Wiggan O, Maloney MT, Bernstein BW, Sneider JM, Gonzalez JA, Bamburg JR: Production and use of replicationdeficient adenovirus for transgene expression in neurons. Methods Cell Biol 2003, 71:387-416.

61. Fjell AM, Walhovd KB, Fennema-Notestine C, McEvoy LK, Hagler DJ, Holland D, Brewer JB, Dale AM, Alzheimer's Disease Neuroimaging Initiative: CSF biomarkers in the prediction of cerebral and clinical change in mild cognitive impairment and Alzheimer's disease. J Neurosci 2010, 30:2088-2101.

62. Portelius E, Bogdanovic N, Gustavsson MK, Volkmann I, Brinkmalm G, Zetterberg $\mathrm{H}$, Winblad B, Blennow K: Mass spectrometric characterization of brain amyloid beta isoform signatures in familial and sporadic Alzheimer's disease. Acta Neuropathol 2010, 120:185-193.

63. Marksteiner J, Humpel C: Beta-amyloid expression, release and extracellular disposition in aged rat brain slices. Mol Psychiatry 2008, 13:939-952.
64. Hung LW, Ciccotosto GD, Giannakis E, Tew DJ, Perez K, Masters CL, Cappai R, Wade JD, Barnham KJ: Amyloid-beta peptide (Abeta) neurotoxicity is modulated by the rate of peptide aggregation: Abeta dimers and trimers correlate with neurotoxicity. J Neurosci 2008, 28:11950-11958.

65. Marsden IT, Minamide LS, Bamburg JR: Amyloid- $\beta$-induced amyloid- $\beta$ secretion: a possible feed-forward mechanism in Alzheimer disease. J Alz Dis 2011.

66. Fuentealba RA, Liu Q, Zhang J, Kanekiyo T, Hu X, Lee JM, LaDu MJ, Bu G: Low-density lipoprotein receptor-related protein 1 (LRP1) mediates neuronal Abeta42 uptake and lysosomal trafficking. PLoS One 2010, 5 e11884.

67. De Felice FG, Vieira MNN, Bomfim TR, Decker H, Velasco PT, Lambert MP, Viola KL, Zhao WQ, Ferreira ST, Klein WL: Protection of synapses against Alzheimer's-linked toxins: Insulin signaling prevents the pathogenic binding of A $\beta$ oligomers. Proc Nat'l Acad Sci USA 2009, 106:1971-1976.

68. Carlisle HJ, Manzerra P, Marcora E, Kennedy MB: SynGAP regulates steadystate and activity-dependent phosphorylation of cofilin. J Neurosci 2008, 28:13673-13683.

69. Yuen EY, Yan Z: Dopamine D4 receptors regulate AMPA receptor trafficking and glutamatergic transmission in GABAergic interneurons of prefronatl cortex. J Neurosci 2009, 14:550-562.

70. Gu J, Lee CW, Fan Y, Komols D, Tang X, Sun C, Chen G, Yu K, Hartzell HC, Bamburg JR, Zheng JQ: ADF/cofilin-mediated actin dynamics regulate AMPA receptor trafficking during synaptic plasticity. Nat Neurosci 2010, 13:1208-1215.

71. Morris RGM: Elements of a neurobiological theory of hippocampal function: the role of synaptic plasticity, synaptic tagging and schemas. Eur J Neurosci 2006, 23:2829-2846.

72. Nakazawa K, Quirk MC, Chitwood RA, Watanabe M, Yeckel MF, Sun LD, Kata A, Carr CA, Johnston D, Wilson MA, Tonegawa S: Requirement for hippocampal CA3 NMDA receptors in associative memory recall. Science 2002, 297:211-218.

73. Bertoni-Freddari C, Fattoretti P, Casoli T, Caselli U, Meier-Ruge W: Deterioration threshold of synaptic morphology in aging and senile dementia of Alzheimer's type. Anal Quant Cytol Histol 1996, 18:209-213.

74. Scheff SW, Price DA: Synaptic pathology in Alzheimer's disease: a review of ultrastructural studies. Neurobiol Aging 2003, 24:1029-1046.

75. Masliah E, Mallory M, Hansen L, Deteresa R, Alford M, Terry R: Synaptic and neuritic alterations during the progression of Alzheimer's disease. Neurosci Lett 1994, 174:67-72.

doi:10.1186/1750-1326-6-10

Cite this article as: Davis et al:: Amyloid beta dimers/trimers potently induce cofilin-actin rods that are inhibited by maintaining cofilinphosphorylation. Molecular Neurodegeneration 2011 6:10.

\section{Submit your next manuscript to BioMed Central and take full advantage of:}

- Convenient online submission

- Thorough peer review

- No space constraints or color figure charges

- Immediate publication on acceptance

- Inclusion in PubMed, CAS, Scopus and Google Scholar

- Research which is freely available for redistribution

Submit your manuscript at www.biomedcentral.com/submit
C Biomed Central 